OPEN ACCESS

Edited by: Amanda Owen,

University of Glasgow, United Kingdom

Reviewed by: Zhixiong Shen,

Coastal Carolina University, United States

Gabor Ujvari, Hungarian Academy of Sciences (MTA), Hungary

*Correspondence:

Stephanie Scheidt stephanie.scheidt@uni-koeln.de

Specialty section: This article was submitted to Sedimentology, Stratigraphy and Diagenesis,

a section of the journal

Frontiers in Earth Science

Received: 24 August 2020 Accepted: 06 November 2020 Published: 15 January 2021

Citation:

Scheidt S, Berg S, Hambach U, Klasen N, Pötter S, Stolz A, Veres D,

Zeeden C, Brill D, Brückner $\mathrm{H}$,

Kusch S, Laag C, Lehmkuhl F, Melles M, Monnens F, Oppermann L,

Rethemeyer J and Nett JJ (2021) Chronological Assessment of the Balta Alba Kurgan Loess-Paleosol Section (Romania) - A Comparative Study on Different Dating Methods for a Robust

and Precise Age Model.

Front. Earth Sci. 8:598448. doi: 10.3389/feart.2020.598448

\section{Chronological Assessment of the Balta Alba Kurgan Loess-Paleosol Section (Romania) - A Comparative Study on Different Dating Methods for a Robust and Precise Age Model}

Stephanie Scheidt ${ }^{1 *}$, Sonja Berg ${ }^{1}$, Ulrich Hambach ${ }^{2,3}$, Nicole Klasen ${ }^{4}$, Stephan Pötter ${ }^{5}$, Alexander Stolz ${ }^{6}$, Daniel Veres ${ }^{7}$, Christian Zeeden ${ }^{8}$, Dominik Brill ${ }^{4}$, Helmut Brückner ${ }^{4}$, Stephanie Kusch ${ }^{9}$, Christian Laag ${ }^{8,10}$, Frank Lehmkuhl ${ }^{5}$, Martin Melles ${ }^{1}$, Florian Monnens ${ }^{1}$, Lukas Oppermann ${ }^{4}$, Janet Rethemeyer ${ }^{1}$ and Janina J. Nett ${ }^{5}$

\footnotetext{
${ }^{1}$ Institute of Geology and Mineralogy, Faculty of Mathematics and Natural Sciences, University of Cologne, Cologne, Germany, ${ }^{2}$ Chair of Geomorphology, Faculty of Biology, Chemistry, and Earth Sciences, University of Bayreuth, Bayreuth, Germany, ${ }^{3}$ Bayreuth Center for Ecology and Environmental Research, University of Bayreuth, Bayreuth, Germany, ${ }^{4}$ Cologne Luminescence Laboratory, Institute of Geography, Faculty of Mathematics and Natural Sciences, University of Cologne, Cologne, Germany, ${ }^{5}$ Chair of Physical Geography and Geoecology, Department of Geography, RWTH Aachen University, Aachen, Germany, ${ }^{6}$ Institute for Nuclear Physics, Faculty of Mathematics and Natural Sciences, University of Cologne, Cologne, Germany, ${ }^{7}$ Institute of Speleology, Romanian Academy, Cluj-Napoca, Romania, ${ }^{8}$ Rock Physics and Borehole Geophysics, Leibniz Institute for Applied Geophysics, Hannover, Germany, ${ }^{9}$ CologneAMS-Centre-Centre for Accelerator Mass Spectrometry, University of Cologne, Cologne, Germany, ${ }^{10}$ Université de Paris, Institut de Physique du Globe de Paris, CNRS, Paris, France
}

Loess-paleosol sequences (LPSs) are important terrestrial archives of paleoenvironmental and paleoclimatic information. One of the main obstacles for the investigation and interpretation of these archives is the uncertainty of their age-depth relationship. In this study, four different dating techniques were applied to the Late Pleistocene to Holocene LPS Balta Alba Kurgan (Romania) in order to achieve a robust chronology. Luminescence dating includes analysis of different grain-size fractions of both quartz and potassium feldspar and the best results are obtained using fine-grained quartz blue-stimulated and polymineral postinfrared infrared-stimulated luminescence measurements. Radiocarbon $\left({ }^{14} \mathrm{C}\right)$ dating is based on the analysis of bulk organic carbon $(\mathrm{OC})$ and compound-specific radiocarbon analysis (CSRA). Bulk OC and leaf wax-derived $n$-alkane ${ }^{14} \mathrm{C}$ ages provide reliable age constraints for the past c. 25-27 kyr. CSRA reveals post-depositional incorporation of roots and microbial OC into the LPS limiting the applicability of ${ }^{14} \mathrm{C}$ dating in older parts of the sequence. Magnetic stratigraphy data reveal good correlation of magnetic susceptibility and the relative paleointensity of the Earth's magnetic field with one another as well as reference records and regional data. In contrast, the application of paleomagnetic secular variation stratigraphy is limited by a lack of regional reference data. The identification of the Campanian Ignimbrite/ $Y-5$ tephra layer in the outcrop provides an independent time marker against which results from the other dating methods have been tested. The most accurate age constraints from each method are used for two Bayesian age-depth modeling approaches. The systematic comparison of the individual results exemplifies the advantages and disadvantages of the respective methods. Taken as a whole, the two age-depth models 
agree very well, our study also demonstrates that the multi-method approach can improve the accuracy and precision of dating loess sequences.

Keywords: loess-paleosol sequences, optically stimulated luminescence dating, magnetic stratigraphy, compoundspecific radiocarbon analysis, tephrochronology, age-depth modeling, Romania, late Pleistocene-Holocene

\section{INTRODUCTION}

Loess-paleosol sequences (LPSs) are widely spread across Central Eastern Europe (Figure 1) and provide archives of paleoclimate information crucial for the reconstruction of the Pleistocene environmental evolution (e.g., Marković et al., 2015). In addition to semi-continuous dust input, the formation of LPSs is closely linked to changes in climate and environmental conditions, which are controlled by interglacial-glacial cycles (Gallet et al., 1996; Kohfeld and Harrison, 2003; Svensson et al., 2008; Újvári et al., 2010; Obreht et al., 2017; Zeeden et al., 2018b). Beyond reconstructing Milankovitch-scale climatic variations, LPSs also allow sub-millennial climatic fluctuations to be identified (Moine et al., 2017; Újvári et al., 2017; Zeeden et al., 2018c; Veres et al., 2018). In LPSs of the last glacial cycle, the imprint of past climatic fluctuations is preserved as a succession of weakly developed paleosols or pedogenetically overprinted loess layers, which often gradually turn into adjacent loess beds. These imprints of orbital to millennial climatic variations provide the backbone for chronostratigraphic correlations (at least) on hemispheric scales and interpretation of deposits across environmental boundaries (e.g., Rousseau et al., 2020). In paleoclimatology, this approach was used even before absolute dating techniques became available (e.g., Emiliani, 1955). Nevertheless, to unambiguously link the characteristic paleoclimatic imprints in sedimentary archives to a precisely defined chronostratigraphic interval, time anchors (tie points) are essential (Govin et al., 2015). In their absence, the chronologies of precisely dated archives (e.g., ice core records, speleothems) and even chronologies derived using astrochronological approaches remain speculative (e.g., Lowe and Walker, 2014). Hence, one of the main obstacles for the investigation and interpretation of climatic and environmental information preserved in sedimentary archives is the uncertainty of the age-depth relationship. Most analytical dating techniques applicable to LPSs have age uncertainties that exceed

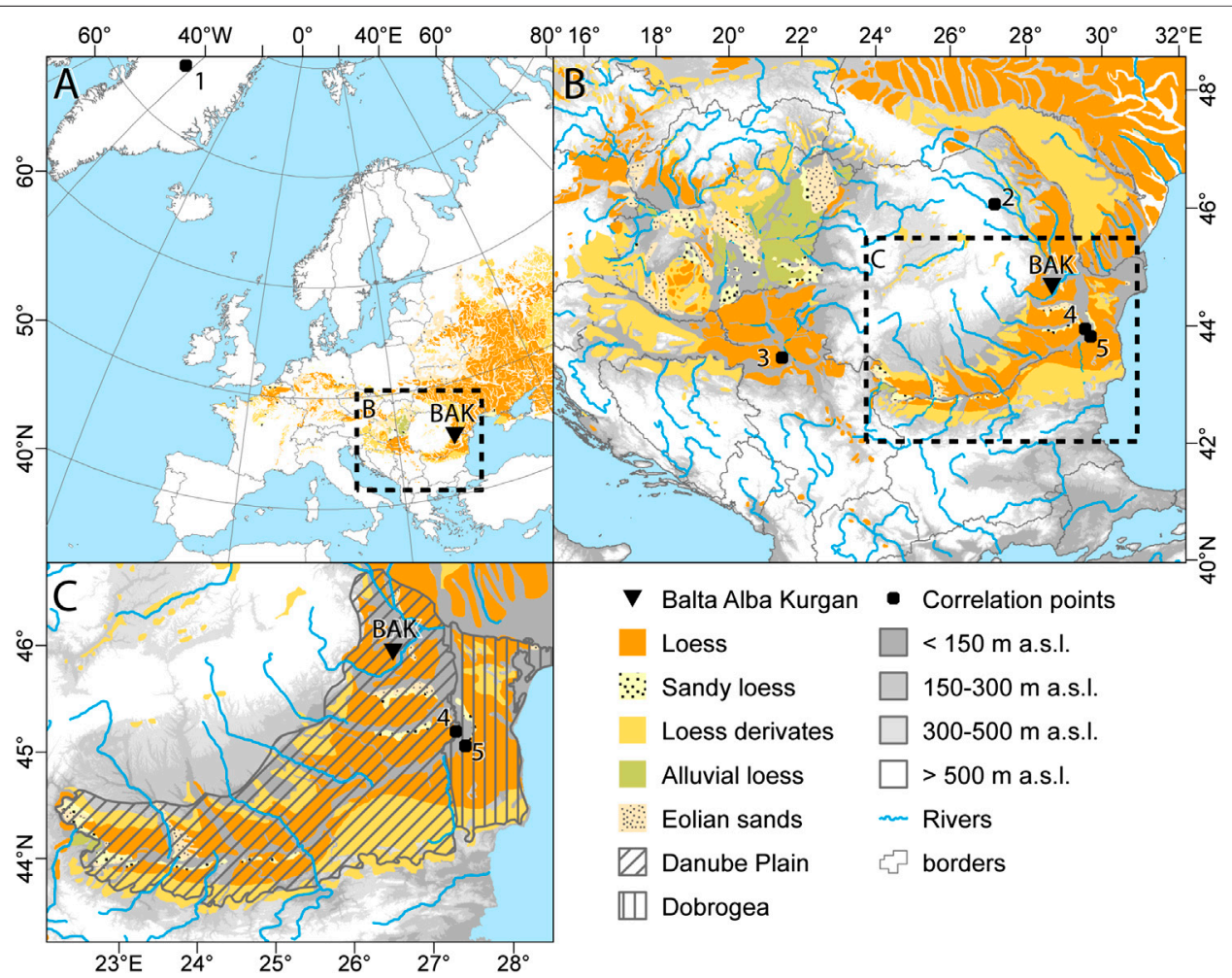

FIGURE 1 | Location of the study area and distribution of eolian sediments (according to Haase et al. (2007), modified). (A) Europe. (B) Southeast Europe. (C) The Lower Danube Basin with landscape units (according to Jipa (2014), modified). Black circles indicate the correlation sites for magnetic stratigraphy as described in Magnetic Stratigraphy. 1) NGRIP, 2) Poiana Ciresului, 3) Batajnica, 4) Vlasca, 5) Rasova. Elevation contours (based on JAXA, 2016) are shown to illustrate the natural altitudinal boundaries of loess distributions. 
millennial-to-centennial-scale resolution. Thus, the exact timing and duration of individual short-term climatic fluctuations can be difficult to establish (e.g., Zeeden et al., 2018c). However, good age control of these events is of particular importance in understanding broad-scale atmospheric circulation patterns, climatic feedback mechanisms and possibly offsets in timing between different regions and deposit types. Therefore, in this study we combine absolute dating techniques (optically stimulated luminescence, radiocarbon) with correlative dating (tephrochronology, relative magnetic paleointensity, magnetic susceptibility correlation) and integrate the results in a robust absolute age model.

Optically stimulated luminescence (OSL) dating is the most commonly used absolute dating technique in loess chronological research (Roberts, 2008). Sediment accumulation is dated directly by measuring a signal that builds up over time in buried quartz and feldspar grains and resets during particle transport. The use of different grain-sizes and mineral extracts and measurement protocols has been well established (Murray and Wintle, 2000; Murray and Wintle, 2003; Timar-Gabor et al., 2011; Buylaert et al., 2012). The ubiquity of suitable sample material in loess, favorable conditions for signal resetting during eolian transport and a dating range covering at least the last interglacial-glacial cycle are the main advantages of this methods for dating LPSs (e.g., Lauer et al., 2016; Bösken et al., 2017; Timar-Gabor et al., 2017; Bösken et al., 2019; Constantin et al., 2019; Lomax et al., 2019; Fenn et al., 2020a). However, the age uncertainties of luminescence methods are on the order of thousands of years, and significant age offsets have also been reported between different mineral fractions dated as well as different protocols applied. In comparison, the age uncertainty of radiocarbon $\left({ }^{14} \mathrm{C}\right)$ analysis of carbonaceous and organic materials is substantially lower allowing centennial-scale resolution chronologies in LPS records (e.g., Song et al., 2012; Újvári et al., 2014c; Song et al., 2015). The method uses the radioactive decay of naturally occurring ${ }^{14} \mathrm{C}$ in organic matter or carbonates to calculate the time since the last equilibration with atmospheric $\mathrm{CO}_{2}$ or other carbon pools (e.g., dissolved inorganic carbon in aquatic environments). Due to the half-life of ${ }^{14} \mathrm{C}$ and analytical limitations, maximum ages of $50-60 \mathrm{ka}$ can typically be resolved with this approach for regular-sized $(\sim 1 \mathrm{mg})$ samples. Since the atmospheric ${ }^{14} \mathrm{C}$ content has changed in the past, ${ }^{14} \mathrm{C}$ ages are calibrated against reference curves to obtain absolute ages (e.g., Reimer et al., 2020). Nonetheless, the application of ${ }^{14} \mathrm{C}$ analysis to loess is frequently limited by the absence/scarcity of suitable remains such as wood, charcoals, bones and carbonate fossils (e.g., Haesaerts et al., 2010; Pigati et al., 2013; Újvári et al., 2014c; Moine et al., 2017). Moreover, ${ }^{14} \mathrm{C}$ ages obtained on bulk organic carbon (OC) can be biased by relocation of organic matter in loess, which may result in an underestimation of sedimentation ages (e.g., Hatté et al., 2001). In contrast to OSL and ${ }^{14} \mathrm{C}$ analyses, magnetic stratigraphy is an indirect and correlative dating approach and includes age uncertainties that are not easily quantified. The method can be used for sediments accumulated beyond the dating limit of radiocarbon and luminescence techniques and is best applied to (several meter) long sequences (Heil et al., 2010; Song et al., 2018a; Zeeden et al., 2018b; Pfeifer et al., 2020; Zeeden et al., 2020). In general, age control is achieved by "wiggle-matching", i.e., tying significant features of paleo- and rock magnetic parameters to independently dated master curves (Maher, 1999; Hambach et al., 2008). The signals used are typically the magnetic susceptibility and, to a lesser extent, the direction and/or relative paleointensity (RPI) of the Earth's magnetic field. If unequivocal correlations are not possible, potential correlations need to be verified using other dating techniques, which may result in an iterative process. While magnetic stratigraphy is a powerful chronostratigraphic tool for LPSs, it should be noted that ages can be younger than the deposition of the respective LPS (Liu et al., 2015), because soils develop on and into accumulated sediments post-depositionally.

The motivation for this study was to compare the results of the individual dating methods and obtain a robust absolute chronology for the LPS Balta Alba Kurgan (in Romanian: Balta Albă Kurgan; hereafter BAK; Figure 1). In this LPS, a well constrained tephra layer is included and forms an independent time marker. We apply luminescence dating, radiocarbon dating and magnetic stratigraphy. In addition to the standard (bulk OC) ${ }^{14} \mathrm{C}$ analysis, we also test the applicability of compound-specific radiocarbon analysis (CSRA) of leaf wax lipids for age determination of loess, a method that has been rarely applied to LPSs (Häggi et al., 2014). We also use an extended set of OSL dating protocols to validate the OSL age assignment, including one for coarse-grain feldspar that is typically not applied to loess in this region. Furthermore, we combine the results with statistical age-depth modeling to obtain a robust chronology of the BAK loess profile. Our approach illustrates the potentials and limitations of each individual method for dating loess sequences and may help to gain a better understanding of the advantages and disadvantages of the individual methods in dating of LPSs. Our observations and conclusions are highly relevant for future studies that focus on the interpretation of loess sequences to study the paleoclimatic and paleoenvironmental evolution in southeastern Europe and elsewhere.

\section{REGIONAL SETTING AND STUDY SITE}

The Lower Danube Basin (LDB) in southeast Romania (Figure 1) is characterized by vast Pleistocene sedimentary deposits of considerable thickness, which are mostly of eolian and fluvial origin. The deposits are incised by broad valleys and alluvial plains of the Danube and its major tributaries. These broad alluvial valleys acted as the major dust source for the coarse components of the loess formed during the Pleistocene (Buggle et al., 2008; Jipa, 2014). The loess deposits of the LDB reach thicknesses of more than $50 \mathrm{~m}$. The thickness and the mean grain size of these loess deposits decrease with distance from potential source areas, i.e., especially the river beds (Smalley and Leach, 1978; Smalley et al., 2009; Jipa, 2014). The most intensively studied LPSs within the LDB are found on the Dobrogea plateau (Figure 1; e.g., Buggle et al., 2009; Buggle et al., 2013; Fitzsimmons and Hambach, 2014; Obreht et al., 2017), along the shores of the Black Sea (e.g., Necula et al., 2015) and along river 


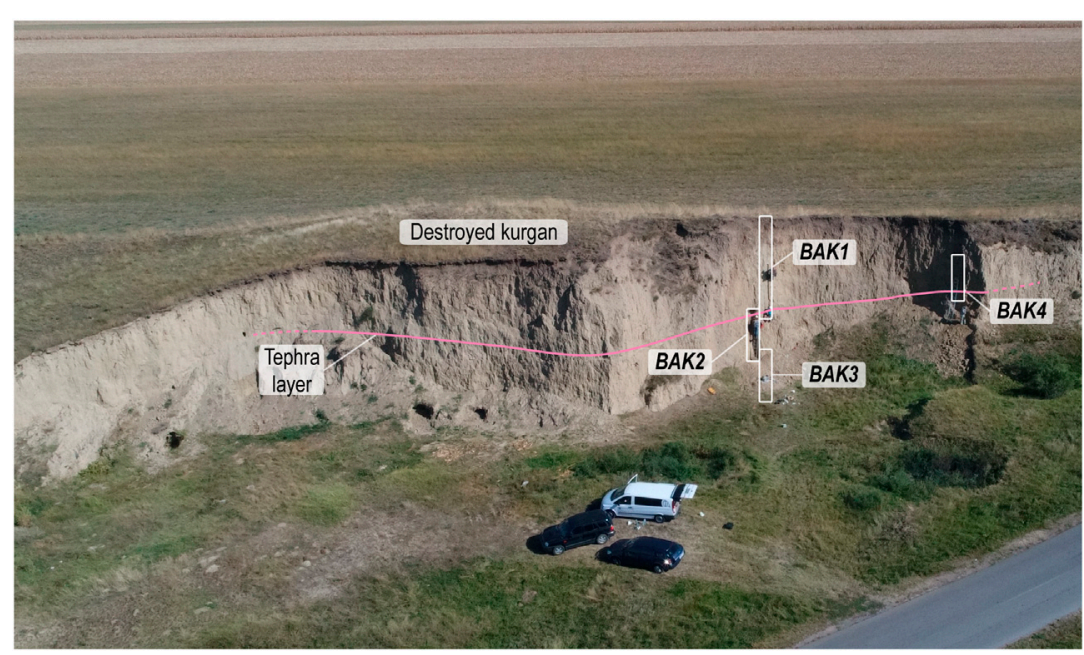

FIGURE 2|Aerial view of the BAK site looking southeast. The location of the kurgan as well as the stratigraphic position of the tephra layer (pink line) are indicated. The sampled sub-profiles are shown with white rectangles.

cuts of the Danube and its tributaries across the Danube Plain (Constantin et al., 2014; Obreht et al., 2017; Antoine et al., 2019; Figure 1). These sections often exhibit several loess-soil couplets representing glacial-interglacial-cycles. The forelands of the Eastern Carpathians, however, are severely underrepresented in loess research, although the area is covered by vast loess deposits. The BAK LPS $\left(45^{\circ} 16^{\prime} 40^{\prime \prime} \mathrm{N}, 27^{\circ} 17^{\prime} 27^{\prime \prime} \mathrm{E}\right.$, ca. $46 \mathrm{~m}$ above mean sea level, Figure 1) is located in this area, approx. $40 \mathrm{~km}$ east of the foothills of the Carpathian Bend. It is exposed at a road cut of road DC13 dissecting the northern slope of a loess plateau between the rivers Râmnicul Sărat and Buzău. The Carpathian foothills to the West comprise thick Neogene deposits. The loess plateau frames a basin that includes the alkaline lake Balta Alba, located approximately $2 \mathrm{~km}$ east of the section. Lake Balta Alba formed during the Holocene due to neotectonic subsidence in a paleo-channel of the Râmnicul Sărat (ILEC, 2019).

The sampled BAK sequence is $\sim 15.4 \mathrm{~m}$ thick. Several large pitgrave burial mounds (kurgans) are preserved in the vicinity of the sampling site. The majority of these tumuli in the Lower Danube area most likely date to the Late Neolithic-Early Bronze Age transition ( 3 ka B.C.; Frînculeasa et al., 2015). Our sampled profiles are located close to the margin of a kurgan (Figures 2, 3). The uppermost $0.78 \mathrm{~m}$ of the profile formed after kurgan construction as indicated by the preservation of a nonploughed topmost horizon of a chernozem. Between 0.78 and $1.55 \mathrm{~m}$ depth, the sediments in the BAK profile consist of disturbed anthropogenic infill of the grave mound. Between $1.55 \mathrm{~m}$ and $2.10 \mathrm{~m}$ depth, the in-situ lower part of the primary Holocene chernozem (S0, nomenclature according to Marković et al., 2015) overlies bioturbated loess with a leopard skin pattern. From $2.10 \mathrm{~m}$ to $7.40 \mathrm{~m}$ depth, the sediment is a typical loess including pedogenetically overprinted intervals between $4.30-5.92 \mathrm{~m}$ and $6.40-6.95 \mathrm{~m}$. A strongly bioturbated paleosol occurs between $7.40 \mathrm{~m}$ and $8.06 \mathrm{~m}$ depth. At $8.06-8.10 \mathrm{~m}$ depth a macroscopically visible tephra layer has been identified as laterally continuous loose pinkish-whitish patches of coarse silt, resembling other tephra occurrences within the Lower Danube loess (Veres et al., 2013; Obreht et al., 2017; Zeeden et al., 2018c). Below the tephra, up to $8.70 \mathrm{~m}$ depth, the loess is carbonate-rich as well as bioturbated and strongly overprinted by pedogenesis. Underneath, a dark reddish paleosol with two to three distinct pedogenetic horizons is present down to $9.85 \mathrm{~m}$ depth. Other (weakly developed) paleosols can be found between $10.0 \mathrm{~m}$ and $10.2 \mathrm{~m}$ depth, as well as between $10.8 \mathrm{~m}$ and $11.4 \mathrm{~m}$ depth and are intercalated with carbonate-rich loess. The underlying loess reaches down to $13.2 \mathrm{~m}$ depth. A clay-rich, dark greyish to blackish paleosol resembling vertisol features with vertical cracks lies underneath, atop a carbonate-rich loess, which becomes increasingly reddish towards a depth of around $14 \mathrm{~m}$. The paleosol between $14.0 \mathrm{~m}$ and $14.5 \mathrm{~m}$ depth exhibits chernozem-like characteristics. It overlies a carbonaterich loess horizon, which turns into loess with sub-mm sized pores filled with organic material at $14.7 \mathrm{~m}$ depth. At the base of the section, waterlogged, hydromorphic loess and sands are present.

\section{MATERIALS AND METHODS}

\section{Sampling}

For our multidisciplinary dating approach, four subsections (BAK1 to BAK4) were defined along the BAK sequence (Figures 2, 3). The composite profile comprises BAK1 (0-8.50 m), BAK2 (8-12 m) and BAK3 (11.5-15.4 m), which are directly adjacent to one another (thus forming a vertical sampling line) and located slightly to the South of the center of the kurgan. BAK4 is situated approximately $10 \mathrm{~m}$ to the South of the main profile (BAK1-3) and spans $3.66 \mathrm{~m}$. Prior to sampling, the outcrops were thoroughly cleaned to obtain fresh and unweathered sediments. Samples for tephrochronological analyses were collected from the visible volcanic ash layer. 


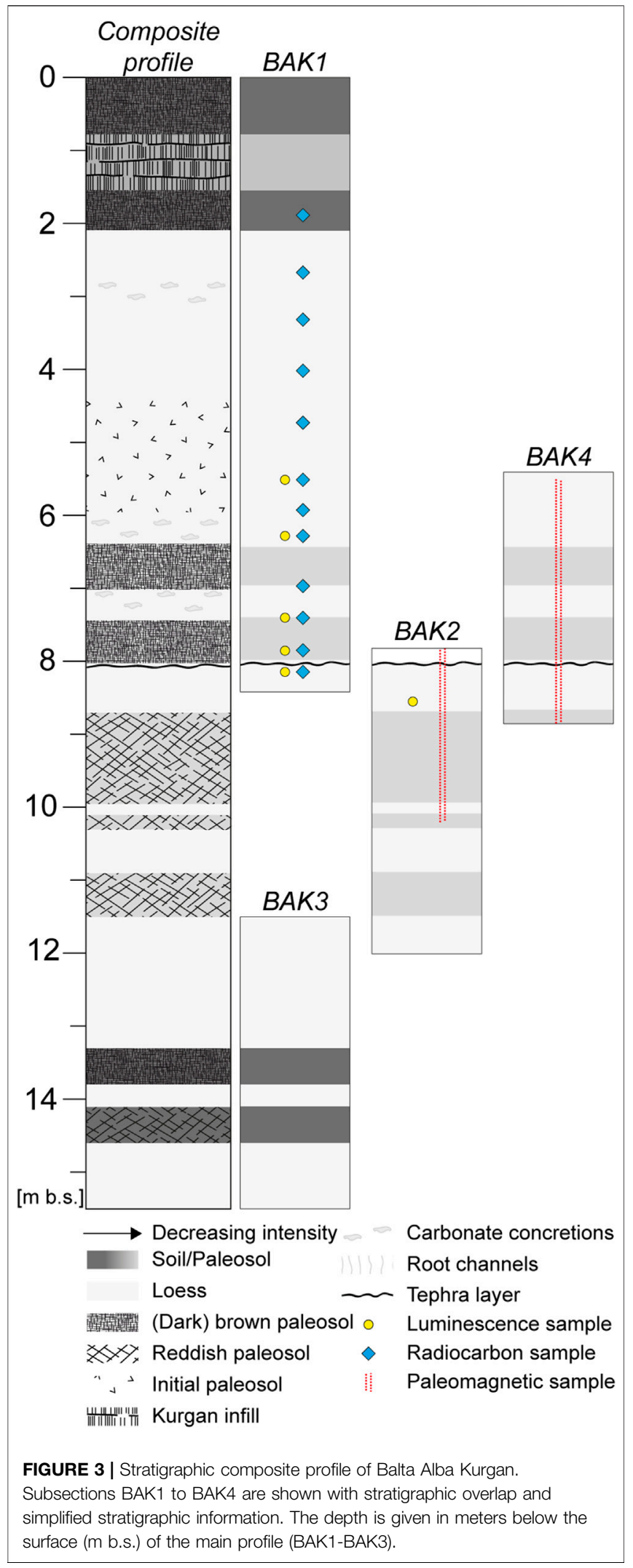

Samples for OSL dating were taken using $20 \mathrm{~cm}$ long metal tubes. Additionally, a sample of the surrounding $30 \mathrm{~cm}$ of sediment was taken for radionuclide analysis (i.e., approximate penetration depth of $\gamma$-radiation). In total, six samples were analyzed in this study. For ${ }^{14} \mathrm{C}$ analysis, twelve samples of $6 \mathrm{~cm}$ thickness ( $\sim 20 \mathrm{~kg}$ of sediment each) adjacent to OSL samples were taken from the BAK1 profile. Oriented paleomagnetic samples were obtained from subsections BAK2 and BAK4 (Figure 2). These subsections allow for cross-correlation with an overlap of approximately $85 \mathrm{~cm}$, which includes the tephra layer. Sampling was performed by inserting square brass tubes of $2 \mathrm{~cm}$ edge length through an orientation frame into the wall. Full spatial orientation was provided by means of magnetic compass measurements combined with an inclinometer to define the dip of the frame. The resulting sediment prisms were subsequently carefully pushed from the tubes into cubic plastic boxes of $8 \mathrm{~cm}^{3}$ volume to retain orientation. The vertical space between the center of the samples is $\sim 2.1 \mathrm{~cm}$. Overall 304 specimens were obtained: 120 from the BAK2 profile and 184 from the BAK4 profile. Twelve additional samples from the BAK1 and BAK2 subsections were selected for mineral magnetic analyses.

\section{Tephra Geochemical Analysis}

Bulk samples collected from the volcanic ash bed identified at BAK were subjected to glass-shard geochemical analyses at the Bayerisches GeoInstitut, University of Bayreuth, Germany. Measurements were performed on thin sections of volcanic glass shards containing sediment embedded in epoxy using a JXA8200 microprobe (JEOL, JP) and single-grain, wavelengthdispersive electron microprobe analysis (WDS-EPMA). Measurements were performed using an accelerating voltage of $15 \mathrm{keV}$ and a $6 \mathrm{nA}$ beam current. Peak counting times were $10 \mathrm{~s}$ for $\mathrm{Na}, 30 \mathrm{~s}$ for $\mathrm{Si}, \mathrm{Al}, \mathrm{K}, \mathrm{Ca}, \mathrm{Fe}$ and $\mathrm{Mg}, 40 \mathrm{~s}$ for $\mathrm{Ti}$ and $\mathrm{Mn}$ and $60 \mathrm{~s}$ for P. Precision is estimated at $<1-6 \%(2 \sigma)$ and $10-25 \%(2 \sigma)$ for major and minor element concentrations, respectively. Geochemical results are summarized in Supplementary Table 6 and an image of the analyzed glass shards is provided in Supplementary Figure 15 of Supplementary Section 4.

\section{Luminescence Dating}

Polymineral fine-grained samples $(4-11 \mu \mathrm{m})$ were prepared for luminescence dating using conventional preparation techniques (Frechen et al., 1996). A separate batch of the fine-grained fraction was etched in $34 \% \mathrm{H}_{2} \mathrm{SiF}_{6}$ for one week to extract fine-grained quartz. Laboratory treatment of sand-sized samples included sieving to isolate the $63-90 \mu \mathrm{m}$ fraction, chemical treatment with $\mathrm{HCl}(10 \%), \mathrm{H}_{2} \mathrm{O}_{2}(10 \%)$ and $\mathrm{Na}_{2} \mathrm{C}_{2} \mathrm{O}_{4}(0.01 \mathrm{~N})$ to remove carbonates, organic material and clay, respectively, as well as density separation $\left(\rho=2.58 \mathrm{~g} \mathrm{~cm}^{-3}, \rho=2.62 \mathrm{~g} \mathrm{~cm}^{-3}\right.$ and $\rho=$ $2.68 \mathrm{~g} \mathrm{~cm}^{-3}$ ) to isolate potassium feldspar and quartz. We used an automated Risø TL/OSL DA 20 reader equipped with a calibrated ${ }^{90} \mathrm{Sr}$ beta source for equivalent dose determination. All samples were prepared and measured in the Cologne Luminescence Laboratory (CLL, University of Cologne, DE). 
Blue light emitting diodes at $470 \mathrm{~nm}(\mathrm{FWHM}=20 \mathrm{~nm})$ were used for the stimulation of the quartz samples and the luminescence signal was detected through a Hoya U-340 filter (blue stimulated luminescence (BSL); Murray and Wintle, 2000; Murray and Wintle, 2003). The initial $0.8 \mathrm{~s}$ of the signal minus a background of the last $4 \mathrm{~s}$ were used. Laboratory experiments included preheat plateau tests using a series of preheat temperatures between $180^{\circ} \mathrm{C}$ and $280^{\circ} \mathrm{C}$ and dose recovery tests. For the dose recovery test, the samples were illuminated with blue light emitting diodes for $100 \mathrm{~s}$ at room temperature and a laboratory dose in the range of the natural dose was given to the samples. Equivalent doses were calculated using the arithmetic mean.

Post-infrared infrared stimulated luminescence measured at $290^{\circ} \mathrm{C}$ (p-IR IRSL 290 or pIRIR $_{290}$; Thiel et al., 2011) and infrared stimulated luminescence measured at $50^{\circ} \mathrm{C}\left(\mathrm{IR}_{50}\right.$; Wallinga et al., 2000) were used to measure the polymineral fine-grained samples and the sand-sized potassium feldspar samples. Stimulation was carried out with infrared diodes $(870 \mathrm{~nm}$, FWHM $=40 \mathrm{~nm}$ ) and the signals were detected through an interference filter $(410 \mathrm{~nm})$. The initial $4 \mathrm{~s}$ of the signal minus a background of the last $20 \mathrm{~s}$ were used. Laboratory experiments included prior-IR stimulation temperature tests (Buylaert et al., 2012) using a range of temperatures from $50^{\circ}$ to $220^{\circ} \mathrm{C}$ and dose recovery tests. For the dose recovery tests, the samples were illuminated for $24 \mathrm{~h}$ in a Hönle SOL2 solar simulator and a laboratory dose in the range of the natural dose was applied to the samples. Equivalent doses were calculated using the arithmetic mean. Fading tests (Auclair et al., 2003) were carried out for all samples for the $\mathrm{IR}_{50}$ measurement protocol. $\mathrm{IR}_{50}$ ages were corrected for fading following the approach of Huntley (2006).

For the determination of the environmental dose rate, radionuclide concentrations of ${ }^{238} \mathrm{U},{ }^{232} \mathrm{Th}$ and ${ }^{40} \mathrm{~K}$ were measured using high-resolution gamma-ray spectrometry. The dose rate was calculated with the open access web-based program DRAC v.1.2 (Durcan et al., 2015), using conversion factors reported by Guérin et al., 2011, alpha-efficiency values of $0.10 \pm 0.014$ (pIRIR 290 ; Schmidt et al., 2018), $0.07 \pm 0.02$ $\left(\mathrm{IR}_{50}\right)$ and $0.04 \pm 0.01$ (BSL) and a water content of $25 \pm 10 \%$ for samples with clay and fine silt contents of about $25-30 \%$ and $15 \pm 10 \%$ for samples with clay and fine silt contents of about $20 \%$. Additionally, the gravimetric water content was determined by weighing before and after drying the dosimetry samples in the oven at $50^{\circ} \mathrm{C}$. The internal beta dose rate contribution of the polymineral and the feldspar samples was calculated assuming a potassium content of $12.5 \pm 0.5 \%$ (Huntley and Baril, 1997). The cosmic dose rate was calculated following Prescott and Hutton (1994). We refer to the Supplementary Section 1 for further details.

\section{Radiocarbon Analysis}

Sediment samples for ${ }^{14} \mathrm{C}$ analysis were oven-dried at $40^{\circ} \mathrm{C}$. For bulk OC ${ }^{14} \mathrm{C}$ analysis, root remains were removed by handpicking prior to subsequent chemical treatment with a standard acid-alkali-acid (AAA) protocol. The purified bulk OC was converted to graphite using an automated graphitization system and analyzed at the CologneAMS facility at the University of Cologne, DE (Rethemeyer et al., 2019). Due to the low OC content of the samples, which produced 0.30 to $0.63 \mathrm{mgC}$ (less than $1 \mathrm{mgC}$ needed for the routine measurement), we determined the background of this specific suite of samples with size matched standards at 42,700 \pm $590{ }^{14} \mathrm{C}$ years $\left(\mathrm{F}^{14} \mathrm{C}=0.0049 \pm 0.0004\right.$, fraction modern, Reimer et al., 2004).

For CSRA, $\sim 1 \mathrm{~kg}$ of the dried sediment was ground in an agate mortar. The total lipid extract (TLE) was sequentially extracted by ultrasonication using methanol $(\mathrm{MeOH}), \mathrm{MeOH}$ : dichloromethane (DCM, 1:1, v/v) and DCM: hexane (Hex, 1:1, $\mathrm{v} / \mathrm{v})$. The TLE was saponified with $0.5 \mathrm{M} \mathrm{KOH}$ in $\mathrm{MeOH}$ and water $(9: 1, \mathrm{v} / \mathrm{v})$ at $80^{\circ} \mathrm{C}$ for $2 \mathrm{~h}$. After addition of water, neutral lipids (including $n$-alkanes) were removed by liquid-liquid phase separation using DCM. For extraction of $n$-alkanoic acids, the remaining $\mathrm{KOH}$ mixture was acidified to $\mathrm{pH} 1$ and the acidfraction was extracted with DCM. $n$-Alkanes were eluted over $\mathrm{SiO}_{2}$ columns with Hex. $n$-Alkanoic acids were methylated with $\mathrm{MeOH}$ and $12 \mathrm{M} \mathrm{HCl}(95: 5, \mathrm{v} / \mathrm{v})$ using $\mathrm{MeOH}$ of known ${ }^{14} \mathrm{C}$ isotopic composition $\left(\mathrm{F}^{14} \mathrm{C}_{\mathrm{MeOH}}=0.0002\right)$ to form fatty acid methyl esters (FAMEs).

Individual $n$-alkane and $n$-alkanoic acid homologs were isolated using a 7680 Agilent gas chromatograph (GC, Agilent Technologies, United States) equipped with a CIS 4 injection system (Gerstel, DE) and coupled to a preparative fraction collector (PFC; Gerstel, DE). Trapping of individual compounds was achieved at room temperature. For subsequent processing, individual compounds were flushed from the glass traps with $1 \mathrm{ml}$ DCM. The purity of each isolated compound was determined by GC-FID (Agilent 7890B, Agilent Technologies, United States) and compounds with purities $>98 \%$ were processed further. Two molecular standards $\mathrm{C}_{18} n$-alkane (Fluka, Prod. No. 74691-5g, Lot. 0001448903 with an $\mathrm{F}^{14} \mathrm{C}$ value of $\left.<0.0008\right)$ and squalane $\left(\mathrm{C}_{30}\right.$ isoprenoid; Fluka, Prod. No. 85629-50 ml, Lot. 0001418796 with an $\mathrm{F}^{14} \mathrm{C}$ value of $\left.1.0187 \pm 0.0033\right)$ were also processed to detect extraneous carbon (blank $\mathrm{C}$ ) introduced during sample handling and PCGC purification.

Compounds were transferred into tin capsules for combustion and ${ }^{14} \mathrm{C}$ analysis with the EA-GIS (elemental analyzer coupled to a gas injection system) periphery at CologneAMS (Stolz et al., 2019). Due to the small and variable sample sizes of the lipid biomarker compounds used for ${ }^{14} \mathrm{C}$ analysis (9-42 $\mu \mathrm{g} \mathrm{C}$, see Supplementary 2, Supplementary Table 2), the extraneous $C$ introduced during combustion in tin capsules and analysis with the EA-GIS set-up was also quantified. Following the procedure described in Hanke et al. (2017) a constant contamination of $1.0 \pm$ $0.1 \mu \mathrm{g} \mathrm{C}$ with an $\mathrm{F}^{14} \mathrm{C}$ value of $0.44 \pm 0.05$ was determined (see Supplementary Section $\mathbf{2 . 2}$ for further details). To assess if the ${ }^{14} \mathrm{C}$ age of a sample is distinguishable from background, the massdependent detection limit was calculated following Hanke et al. (2017). For example, the mass-dependent detection limit of a sample with a mass of $16 \mu \mathrm{g} \mathrm{C}(\mathrm{Col6363})$ was $\mathrm{F}^{14} \mathrm{C}=0.015$, corresponding to $\sim 38,000{ }^{14} \mathrm{C}$ yr BP (Supplementary Figure 7). $\mathrm{F}^{14} \mathrm{C}$ values of all compound samples were corrected for the PCGC processing blank $\left(\mathrm{F}^{14} \mathrm{C}=0.25 \pm 0.017\right.$ and $\left.0.6 \pm 0.3 \mu \mathrm{g} \mathrm{C}\right)$ 
and FAMEs for the addition of one methyl group added during transesterification using mass balance.

\section{Magnetic Stratigraphy}

For age determination using magnetic stratigraphy, the variations of the relative paleointensity (RPI) of the Earth's magnetic field recorded in the loess sequence and the magnetic susceptibility of the sediment were used. Magnetic measurements were conducted in different laboratories. A list of the devices used in the individual labs is given in Supplement 2 (Supplementary Table 4). The measurements performed include determination of the mass and the magnetic susceptibility (given as mass specific magnetic susceptibility $x$ ) and frequency dependence of magnetic susceptibility $\left(\kappa_{\mathrm{FD}}\right)$ of the oriented samples. The measurement of the natural remanent magnetization (NRM) was followed by progressive alternating field (AF) demagnetization in 12 steps up to $80 \mathrm{mT}$. The data was plotted in orthogonal vector diagrams (Zijderveld, 1967) and analyzed using the program Remasoft 3.0 (Chadima and Hrouda, 2006). The characteristic remanent magnetization (ChRM) was isolated using principal component analysis (Kirschvink, 1980) embedded in the Remasoft 3.0 software (Chadima and Hrouda, 2006). For most samples the ChRM was determined between the $15 \mathrm{mT}$ and the $40 \mathrm{mT}$ AF step. In every second sample, an anhysteretic remanent magnetization (ARM) was imparted by superposition of a $100 \mu \mathrm{T}$ DC field and $100 \mathrm{mT}$ alternating field. Subsequently the ARM was demagnetized in a $25 \mathrm{mT}$ alternating field. The RPI was determined as suggested by Levi and Banerjee (1976), i.e., dividing the remanence of the sample measured after $25 \mathrm{mT}$ AF demagnetization by the remanence of the ARM after the $25 \mathrm{mT}$ AF demagnetization. The value of $25 \mathrm{mT}$ was chosen to ensure magnetic cleaning of viscose remanence, whilst a reasonable amount of magnetization is still preserved. Furthermore, mineral magnetic investigations were performed on 12 selected samples to ascertain whether the sediment had preserved paleomagnetic information over geological time scales. Besides determination of the hysteresis parameters, the temperature dependence of the magnetic susceptibility ( $\kappa_{\mathrm{TD}}$ ) was measured.

To provide chronostratigraphic constraints by magnetic stratigraphy we correlate the magnetic properties of the BAK site to those of independently dated reference records. We visually align our RPI data with the upgraded version of the high-resolution global paleointensity stack GLOPIS-75 (Laj et al., 2004) and GLOPIS-GICC05 (Laj and Kissel, 2015). Additionally, we compare the data with the RPI values gained from the archaeological site of Poiana Ciresului in northeastern Romania (Figure 1; Zeeden et al., 2009; Zeeden et al., 2011). To reduce noise, the RPI of the BAK profile is smoothed with a three-point running average. Please note that the original age model of Poiana Ciresului (Zeeden et al., 2009; Zeeden et al., 2011; Zeeden et al., 2020; Zeeden and Hambach, 2020) is based on an RPI correlation for which the Laschamp geomagnetic excursion is set at $38.5 \mathrm{ka}$ BP instead of $41 \mathrm{ka} \mathrm{BP}$ (Laj and Kissel 2015). We therefore show an adjusted age model in this study that correlates the four tie points used in Zeeden et al. (2009) with GLOPIS-GICC05. We also compare the magnetic susceptibility data of the BAK pmag composite to the NGRIP $\delta^{18} \mathrm{O}$ record (Andersen et al., 2004) and to different loess records from the region (Figure 1). As for the RPI correlation, the individual tie points result from wiggle matching of prominent fluctuations. For the time interval of interest, we use the data of the loess sites Rasova (Figure 1; Zeeden et al., 2016; Zeeden et al., 2018c; Zeeden et al., 2019) and Vlasca in Romania (Figure 1; Obreht et al., 2017). Please note that the magnetic susceptibility of Vlasca below the Campanian Ignimbrite/Y-5 tephra layer includes new data for which the age model is preliminary only. Additionally, we correlate $\mathrm{BAK}$ to the magnetic susceptibility record of the Batajnica site in Serbia (Figure 1; Marković et al., 2009; Basarin et al., 2014) for which OSL ages have recently been published (Avram et al., 2020). An overview of the data used for the age models at the respective loess sites used for correlation with the BAK site is shown in Supplementary Table 3.

The age models resulting from the paleomagnetic dating approaches arise from linear interpolation between age tie points. The age-depth relationship was linearly extended to include the top and the bottom of the sequence.

\section{Age Modeling}

To combine the age information of the individual dating methods, we used two different Bayesian age-depth modeling approaches. The Bchron software (Parnell et al., 2008; Parnell, 2018) runs in the $R$ environment ( $R$ Core Team, 2020). The BChron age-depth modeling approach relies on an increasing sediment column and a gamma distribution as prior information for a sediment accumulation model. The ages and their uncertainties are assumed to be correct. We also apply the ADMin approach (Zeeden et al., 2018a), which is originally tailored to luminescence ages. Here, we apply this model to the combination of ages from different dating methods. Initially, it reconstructs a probability density for the random and systematic parts of uncertainty, which represent unsystematic random effects and a possibly systematic offset, respectively. It then uses the random part for modeling and recombines the model results with systematic uncertainty. This model defines no priors about sedimentation rates, but resamples ages and uncertainty 'as is' and uses combinations, which represent chronological order.

After careful inspection of the results, individual age data for each method were selected as described below (Luminescence dating, Radiocarbon Analysis and Magnetic Stratigraphy). ${ }^{14} \mathrm{C}$ ages are calibrated using the IntCal20 dataset (Reimer et al., 2020) and reported using the $2 \sigma$ uncertainty ranges (Table 2 ). When multiple ${ }^{14} \mathrm{C}$ ages were included from individual layers, they were combined by averaging calibrated age ranges. An uncertainty of $10 \%$ is assigned to the ages resulting from magnetic stratigraphy in order to provide a conservative estimate. Reported OSL ages are given with $1 \sigma$ uncertainty, which is considered as such in the age model. The tephra layer identified as the Campanian Ignimbrite/Y-5 (see Tephrochronology) is embedded in the age model using its reported ${ }^{40} \mathrm{Ar} /{ }^{39} \mathrm{Ar}$ age of $39.85 \pm 0.14 \mathrm{ka}$ (Giaccio et al., 2017). Please note, calibrated radiocarbon ages refer to AD 1950, while there is no reference date for luminescence dating and 


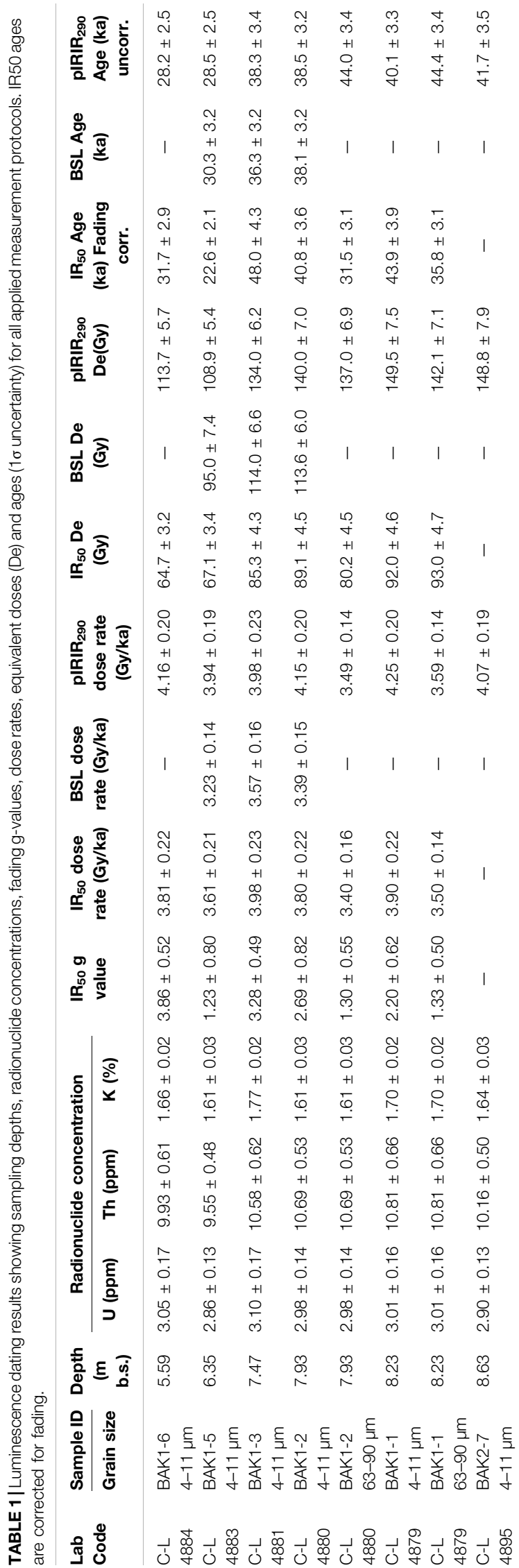

magnetic stratigraphy. For modeling, we did not adjust ages to a common reference point in time, since the offset of c. 70 years is well within the uncertainty ranges of the respective methods and also falls within the temporal resolution of our sampling intervals (which is $\sim 100 \mathrm{yr}$ for magnetic stratigraphy and $\sim 200 \mathrm{yr}$ for OSL and ${ }^{14} \mathrm{C}$ dating). Therefore, adjusting the age scales in this study would imply a degree of precision that is not appropriate. The $\mathrm{R}$ script for age-depth modeling and data interpolation is available in the Supplements 5 and 6.

\section{RESULTS}

\section{Tephrochronology}

Analyses of glass shards from the visible tephra show homogeneous $\mathrm{SiO}_{2}$ concentrations averaging $60.76 \mathrm{wt} \%$, associated with $18.41 \mathrm{wt} \% \mathrm{Al}_{2} \mathrm{O}_{3}, 2.77 \mathrm{wt} \% \mathrm{FeO}, 0.40 \mathrm{wt} \%$ $\mathrm{TiO}_{2}, 1.69 \mathrm{wt} \% \mathrm{CaO}, 5.97 \mathrm{wt} \% \mathrm{Na}_{2} \mathrm{O}$ and $7.02 \mathrm{wt} \% \mathrm{~K}_{2} \mathrm{O}$ (for full details on analytical data see Supplement 4, Supplementary Tables 6 and 7). The typical phonolite to trachyte composition of glass shards suggests that the tephra layer at BAK pertains to the Campanian Ignimbrite/Y-5 tephra (CI/Y5). This volcanic ash layer has been visually and geochemically identified in many loess sequences throughout the Lower Danube Basin (Constantin et al., 2012; Fitzsimmons et al., 2013; Veres et al., 2013; AnechiteiDeacu et al., 2014; Obreht et al., 2017), where it forms an important stratigraphic marker horizon and chronological tiepoint (Zeeden et al., 2018c) with an ${ }^{40} \mathrm{Ar} /{ }^{39} \mathrm{Ar}$ age of $39.85 \pm$ 0.14 ka (Giaccio et al., 2017).

\section{Luminescence Dating}

The fine-grained quartz samples showed bright BSL signals with a fast signal decay (Supplement 1, Supplementary Figure 1). Preheat plateau tests for quartz sample BAK1-2 revealed no dependency of the equivalent dose with temperatures between 180 and $280^{\circ} \mathrm{C}$. For sample BAK1-5, we did not observe a dependency of the equivalent dose with temperatures between 180 and $200^{\circ} \mathrm{C}$ (Supplementary Figure 2A). Dose recovery tests for samples BAK1-2, BAK1-3 and BAK1-5 showed that the laboratory given dose was recovered within $<5 \%$ of unity for the three samples (Supplementary Figure 3). We have calculated equivalent doses with an arithmetic mean to $95.0 \pm 7.4 \mathrm{~Gy}$ (BAK1-5; $6.35 \mathrm{~m}$ depth), $114.0 \pm 6.6 \mathrm{~Gy}$ (BAK1-3; $7.47 \mathrm{~m}$ depth) and $113.6 \pm 6.0 \mathrm{~Gy}$ (BAK1-2; $7.93 \mathrm{~m}$ depth). Dose rates range from $3.23 \pm 0.14 \mathrm{~Gy} / \mathrm{ka}$ to $3.57 \pm 0.16 \mathrm{~Gy} / \mathrm{ka}$. The quartz luminescence ages were calculated to $30.3 \pm 3.2 \mathrm{ka}$ (BAK1-5), $36.3 \pm 3.2 \mathrm{ka}$ (BAK1-3) and $38.1 \pm 3.2 \mathrm{ka}$ (BAK1-2; Table 1). All OSL ages are depicted in Figure 4.

Typical IR50 and pIRIR290 signals are depicted in Supplementary Figure 1. First IR stimulation temperature tests showed no dependency of the equivalent dose on the stimulation temperature, which indicates signal stability (Buylaert et al., 2012; Supplementary Figure 2B). Dose recovery tests indicate that laboratory given doses were recovered within $<5 \%$ of unity for the $\mathrm{IR}_{50}$ and $\mathrm{pIRIR}_{290}$ signals of potassium feldspars and polymineral fine-grained samples BAK1-3 $(7.47 \mathrm{~m})$, BAK1-2 $(7.93 \mathrm{~m})$ and BAK2-7 


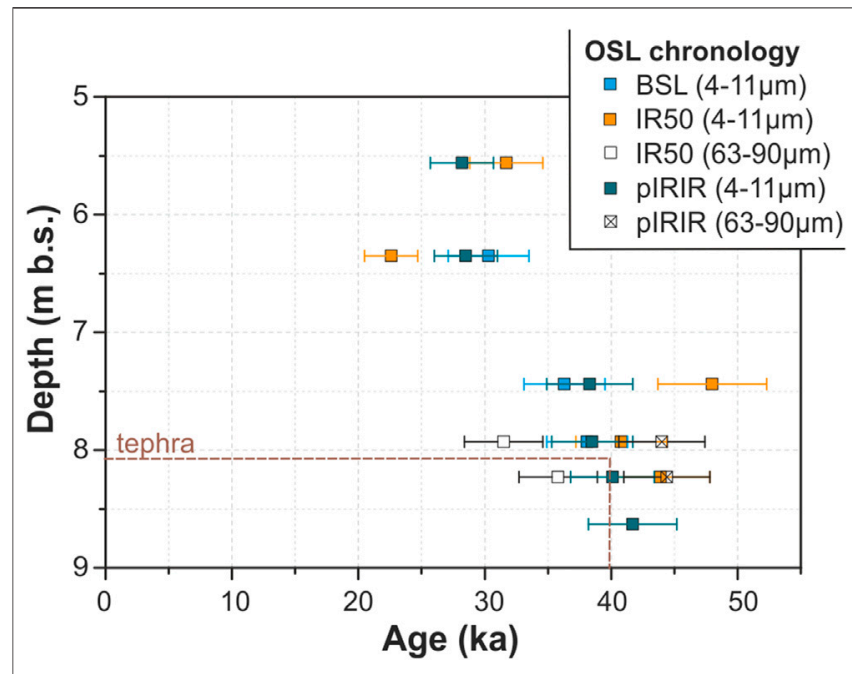

FIGURE 4 | Luminescence ages depicted in an age-depth plot. The location of the tephra layer is shown with a dashed line. OSL ages are given as average and error bars show standard error $(1 \sigma)$.

(8.63 m; Figure 3). We measured fading rates between $1.30 \pm$ $0.55 \% \mathrm{~g}_{2 \text { days }}$ and $3.86 \pm 0.52 \mathrm{~g}_{2 \text { days }}$ for the $\mathrm{IR}_{50}$ signals and between $-2.01 \pm 0.37 \% \mathrm{~g}_{2 \text { days }}$ and $-0.06 \pm 0.06 \% \mathrm{~g}_{2 \text { days }}$ for the pIRIR $_{290}$ signals. Mean equivalent doses are lower for $\mathrm{IR}_{50}$ measurements ranging from $64.7 \pm 3.2 \mathrm{~Gy}$ to $93.0 \pm 4.7 \mathrm{~Gy}$ for $\mathrm{IR}_{50}$ and from $108.9 \pm 5.4 \mathrm{~Gy}$ to $149.5 \pm 7.5 \mathrm{~Gy}$ for $\mathrm{pIRIR}_{290}$ (Table 1). Dose rates are between $3.40 \pm 0.16 \mathrm{~Gy} / \mathrm{ka}$ and $3.98 \pm$ $0.23 \mathrm{~Gy} / \mathrm{ka}$ for $\mathrm{IR}_{50}$ and between $3.49 \pm 0.14 \mathrm{~Gy} / \mathrm{ka}$ and $4.25 \pm$ $0.2 \mathrm{~Gy} / \mathrm{ka}$ for $\mathrm{pIRIR}_{290}$, respectively. This results in fading corrected $\mathrm{IR}_{50}$ ages between $22.6 \pm 2.1 \mathrm{ka}$ and $43.9 \pm 3.9 \mathrm{ka}$ (Figure 4). Post-IRIR 290 ages for the corresponding samples are between $28.2 \pm 2.5 \mathrm{ka}$ and $44.4 \pm 3.4 \mathrm{ka}$ (Figure 4). The pIRIR ages were not fading corrected due to the low values measured. The calculated ages of both sample sets are in good agreement for $50 \%$ of the samples and results differ for those samples with low fading rates $\left(\sim 1.3 \% \mathrm{~g}_{2 \text { days }}\right)$ as well as for sample BAK1-3 $(7.47 \mathrm{~m}$ depth; Table 1).

\section{Radiocarbon Dating}

Twelve bulk OC ${ }^{14} \mathrm{C}$ ages were obtained for subsection BAK1 (Figure 3). In the following, conventional ${ }^{14} \mathrm{C}$ ages are reported. The uppermost sample collected from the Holocene soil at $1.90 \mathrm{~m}$ depth provided an age of 6,440 $\pm 60{ }^{14} \mathrm{C}$ yr BP (Table 2; Figure 5). Up to $7.05 \mathrm{~m}$ depth, ${ }^{14} \mathrm{C}$ ages increase with depth and appear in stratigraphic order $\left(28,400 \pm 280{ }^{14} \mathrm{C}\right.$ yr BP at $\left.7.05 \mathrm{~m}\right)$. Below $7.05 \mathrm{~m}$ depth, ${ }^{14} \mathrm{C}$ ages range from $27,300 \pm 220$ to $29,100 \pm$ $220{ }^{14} \mathrm{C}$ yr BP and are either reversed or agree in consecutive depth intervals (Figure 5).

Compound-specific ${ }^{14} \mathrm{C}$ ages of $n$-alkanes and $n$-alkanoic acids were analyzed for four depths (Table 2; Figure 5). In general, the ${ }^{14} \mathrm{C}$ ages of $n$-alkanoic acids increase with increasing molecular weight (chain length). At $3.35 \mathrm{~m}$ depth, $n-\mathrm{C}_{16}$ alkanoic acid has an age of $2,430 \pm 110{ }^{14} \mathrm{C} \mathrm{yr} \mathrm{BP}$, while $n-\mathrm{C}_{26}$ and $n-\mathrm{C}_{28+30}$ alkanoic acids have ${ }^{14} \mathrm{C}$ ages of $14,300 \pm 230$ and 15,100 \pm $230{ }^{14} \mathrm{C}$ yr BP, respectively. The $n-\mathrm{C}_{29+31}$ alkanes are slightly older than the $n-\mathrm{C}_{28+30}$ alkanoic acids $\left(15,950 \pm 170{ }^{14} \mathrm{C}\right.$ yr BP $)$. At $4.77 \mathrm{~m}$ depth, one ${ }^{14} \mathrm{C}$ age could be obtained for $n-\mathrm{C}_{24+26}$ alkanoic acids $\left(18,700 \pm 190{ }^{14} \mathrm{C}\right.$ yr BP $)$. Concurrent $n-\mathrm{C}_{29}$ and $n$ - $\mathrm{C}_{31}$ alkanes are older $\left(21,600 \pm 290{ }^{14} \mathrm{C} \mathrm{yr} \mathrm{BP}\right.$ and $22,000 \pm$ $310{ }^{14} \mathrm{C}$ yr BP, respectively) than the $n-\mathrm{C}_{24+26}$ alkanoic acids. At $6.35 \mathrm{~m}$ depth, a total of 5 compounds could be analyzed. Analogous to the sample from $3.35 \mathrm{~m}$ depth, ${ }^{14} \mathrm{C}$ ages increase with increasing chain length: $n-\mathrm{C}_{16}$ alkanoic acid has an age of $3,190 \pm 115{ }^{14} \mathrm{C}$ yr BP, $n-\mathrm{C}_{24}$ alkanoic acid $\left(17,850 \pm 230{ }^{14} \mathrm{C} \mathrm{yr}\right.$ $\mathrm{BP})$ and $n-\mathrm{C}_{26}$ alkanoic acid $\left(22,500 \pm 370{ }^{14} \mathrm{C} \mathrm{yr} \mathrm{BP}\right)$ are younger than $n-\mathrm{C}_{28+30}$ alkanoic acids $\left(25,000 \pm 350{ }^{14} \mathrm{C} \mathrm{yr} \mathrm{BP}\right)$. The value obtained for the $n-\mathrm{C}_{29+31}$ alkanes shows the highest ${ }^{14} \mathrm{C}$ age $\left(29,200 \pm 570{ }^{14} \mathrm{C}\right.$ yr BP $)$. At $7.47 \mathrm{~cm}$ depth, $n-\mathrm{C}_{24+26}$ alkanoic acids $\left(23,100 \pm 290{ }^{14} \mathrm{C}\right.$ yr BP $)$ are younger than $n-\mathrm{C}_{29+31+33}$ alkanes $\left(28,400 \pm 420{ }^{14} \mathrm{C}\right.$ yr BP) in agreement with the age patterns observed in the overlying samples.

\section{Magnetic Stratigraphy}

The paleomagnetic samples of subsections BAK2 and BAK4 were combined into a composite profile by aligning their magnetic susceptibility curves (Supplement 3, Supplementary Figure 8). The depth scale of this BAK pmag composite corresponds to the depth scale of the main profile (BAK1-3). Overall, 236 oriented samples are included, of which the upper 109 and lower 127 originate from the BAK4 and the BAK2 profile, respectively. The magnetic properties are reported and discussed in Supplementary Section 3 (Mineral Magnetic analyses and paleomagnetic evidence).

In contrast to the absolute dating techniques used in this study, the ages obtained via correlation of the magnetic evidence of the BAK site with reference records (Supplementary Table 3) are a result of correlative interpretation (see Magnetic Stratigraphy). Because of the scarcity of high resolution paleomagnetic records from the region for the relevant time range, the directional data do not contribute to the magnetic stratigraphy in this study. However, directional data of the ChRM of the BAK pmag composite are available in the Supplementary Section 3.3, including a comparison with the inclination and the declination determined at the Poiana Ciresului site.

\section{DISCUSSION}

\section{Luminescence Dating}

Dating of quartz (BSL) is often deemed to be the most reliable luminescence technique, because quartz signals bleach quickly during transport allowing the signal to build up from zero after deposition. In contrast, feldspar and polymineral $\mathrm{IR}_{50}$ signals bleach at a lower rate, but might suffer from signal loss (anomalous fading) after deposition (Wintle, 1973). Feldspar and polymineral pIRIR signals show the slowest bleaching rates, but are supposedly less prone to anomalous fading (Buylaert et al., 2012). The signal loss can be corrected for, but fading correction requires various assumptions (Thomsen et al., 2008; Guérin et al., 2015). Due to the different bleaching rates, similar ages for three different signals of the same sample are a reliable indicator of complete resetting of the luminescence signal prior to deposition (Murray et al., 2012; Klasen et al., 2018). 
TABLE 2 | Radiocarbon isotope data and ages obtained on bulk organic carbon (bulk OC) and $n$-alkanes and $n$-alkanoic acids (alk. acids). Calibrated ages are given as $2 \sigma$ uncertainty ranges.

\begin{tabular}{|c|c|c|c|c|c|c|}
\hline $\begin{array}{l}\text { Depth } \\
\text { (m b.s.) }\end{array}$ & Sample ID & AMS ID & Dated material & $F^{14} C$ & ${ }^{14} \mathrm{C}$ age (year $\mathrm{BP}$ ) & Age (year cal BP) \\
\hline 1.9 & BAK1-11 & Col6033 & Bulk OC & $0.4483 \pm 0.0033$ & $6,440 \pm 60$ & $7,255-7,432$ \\
\hline 2.69 & BAK 1-10 & Col6034 & Bulk OC & $0.2356 \pm 0.0025$ & $11,600 \pm 90$ & $13,299-13,612$ \\
\hline \multirow[t]{5}{*}{3.35} & BAK1-9 & Col6035 & Bulk OC & $0.1212 \pm 0.0019$ & $16,950 \pm 130$ & $20,178-20,835$ \\
\hline & & Col6355 & $n-\mathrm{C}_{29+31}$ alkane & $0.1370 \pm 0.0029$ & $15,950 \pm 170$ & $18,883-19,588$ \\
\hline & & Col6359 & $n-\mathrm{C}_{16}$ alk. acid & $0.7387 \pm 0.0097$ & $2,430 \pm 110$ & $2,302-2,754$ \\
\hline & & Col6360 & $n-\mathrm{C}_{26}$ alk. acid & $0.1684 \pm 0.0047$ & $14,300 \pm 230$ & $16,869-18,166$ \\
\hline & & Col6361 & $n-C_{28+30}$ alk. acid & $0.1526 \pm 0.0042$ & $15,100 \pm 230$ & $17,903-18,852$ \\
\hline 4.05 & BAK1-8 & Col6036 & Bulk OC & $0.0870 \pm 0.0012$ & $19,600 \pm 110$ & $23,267-23,846$ \\
\hline \multirow[t]{4}{*}{4.77} & BAK1-7 & Col6037 & Bulk OC & $0.0582 \pm 0.0012$ & $22,800 \pm 160$ & $26,467-27,457$ \\
\hline & & Col6356 & $n-\mathrm{C}_{29}$ alkane & $0.0680 \pm 0.0024$ & $21,600 \pm 290$ & $25,234-26,429$ \\
\hline & & Col6357 & $n-C_{31}$ alkane & $0.0644 \pm 0.0025$ & $22,000 \pm 310$ & $25,801-27,059$ \\
\hline & & Col6362 & $n-\mathrm{C}_{24+26}$ alk. acid & $0.0972 \pm 0.0022$ & $18,700 \pm 190$ & $22,324-22,997$ \\
\hline 5.59 & BAK1-6 & Col6038 & Bulk OC & $0.0495 \pm 0.0011$ & $24,100 \pm 180$ & $27,856-28,707$ \\
\hline 5.94 & BAk1-5b & Col6039 & Bulk OC & $0.0438 \pm 0.0012$ & $25,100 \pm 210$ & 28,968-29,951 \\
\hline \multirow[t]{6}{*}{6.35} & BAK1-5 & Col6040 & Bulk OC & $0.0345 \pm 0.0011$ & $27,000 \pm 240$ & $30,831-31,632$ \\
\hline & & Col6358 & $n-C_{29+31}$ alkane & $0.0264 \pm 0.0019$ & $29,200 \pm 570$ & $31,953-34,612$ \\
\hline & & Col6363 & $n-\mathrm{C}_{16}$ alk. acid & $0.6723 \pm 0.0092$ & $3,190 \pm 115$ & 3,076-3,691 \\
\hline & & Col6364 & $n-\mathrm{C}_{24}$ alk. acid & $0.1083 \pm 0.0030$ & $17,850 \pm 230$ & $20,988-22,226$ \\
\hline & & Col6365 & $n-\mathrm{C}_{26}$ alk. acid & $0.0606 \pm 0.0026$ & $22,500 \pm 370$ & $25,967-27,416$ \\
\hline & & Col6366 & $n-C_{28+30}$ alk. acid & $0.0446 \pm 0.0019$ & $25,000 \pm 350$ & $27,704-29,053$ \\
\hline 7.05 & BAK1-4 & Col6041 & Bulk OC & $0.0290 \pm 0.0010$ & $28,400 \pm 280$ & $31,768-33,502$ \\
\hline \multirow[t]{3}{*}{7.47} & BAK1-3 & Col6042 & Bulk OC & $0.0334 \pm 0.0009$ & $27,300 \pm 220$ & $31,082-31,694$ \\
\hline & & Col6663 & $n-\mathrm{C}_{29+31+33}$ alkane & $0.0291 \pm 0.0015$ & $28,400 \pm 420$ & $31,575-33,819$ \\
\hline & & Col6664 & $n-\mathrm{C}_{24+26}$ alk. acid & $0.0563 \pm 0.0020$ & $23,100 \pm 290$ & $26,515-27,840$ \\
\hline 7.93 & BAK1-2 & Col6043 & Bulk OC & $0.0271 \pm 0.0008$ & $28,900 \pm 240$ & $32,322-34,198$ \\
\hline 8.23 & BAK1-1 & Col6044 & Bulk OC & $0.0266 \pm 0.0007$ & $29,100 \pm 220$ & $33,099-34,248$ \\
\hline
\end{tabular}

Ideally, we can distinguish a partially bleached signal from a completely bleached signal by comparison of the fading corrected $\mathrm{IR}_{50}$ with the pIRIR 290 signal and the BSL signal. We applied this approach to samples from three depth intervals. For sample BAK1-2 (4-11 $\mu \mathrm{m} ; 7.93 \mathrm{~m}$ depth), the obtained ages are similar for all three protocols and we conclude that fading correction of the $\mathrm{IR}_{50}$ signal was successful and the luminescence signal was completely reset prior to deposition. A complete reset would be expected for eolian sediments. For this sample, all three protocols appear to be equally suitable for dating. For sample BAK1-5 (4-11 $\mu \mathrm{m}, 6.35 \mathrm{~m}$ depth), BSL and pIRIR 290 ages are in good agreement, while the $\mathrm{IR}_{50}$ age is younger. This is likely due to the low fading rate of $1.23 \pm 0.8 \%$. For sample BAK1$3\left(4-11 \mu \mathrm{m}, 7.47 \mathrm{~m}\right.$ depth), BSL and pIRIR $_{290}$ ages agree well ruling out incomplete bleaching, while the $\mathrm{IR}_{50}$ age is significantly older (Table 1). For two of the three samples, the $\mathrm{IR}_{50}$ luminescence signal in combination with fading correction results in different age estimates, which is most likely due to the $\mathrm{IR}_{50}$ fading correction and the underlying assumptions included in the modeling approach (Thomsen et al., 2008; King et al., 2018). Therefore, for dating the BAK profile we regard the fading corrected $\mathrm{IR}_{50}$ ages to be less robust than the pIRIR $_{290}$ ages obtained on the polymineral fine grain fraction. As outlined above, the BSL and $\mathrm{pIRIR}_{290}$ protocols provide equally robust age estimates for the BAK profile. However, we focused on $\mathrm{pIRIR}_{290}$ dating for the lowermost samples, because we did not want to rely solely on quartz dating for ongoing measurements of older samples (not presented here) as it was shown that quartz signals are problematic for doses above $150 \mathrm{~Gy}$ (fine-grain) and $250 \mathrm{~Gy}$ (coarse-grain), respectively (Avram et al., 2020). Nevertheless, the corresponding quartz and pIRIR 290 ages of samples BAK1-2, BAK1-3 and BAK1-5 are a good indicator that $\operatorname{PIRIR}_{290}$ is a suitable dating protocol for the section.

Part of the uncertainty related to the luminescence age calculation is the estimation of the paleo-water content. Most studies use an average water content value for the entire period between sediment accumulation and sampling. For most samples, this period covers different paleoclimatic conditions, suggesting that sediment water contents are not constant. For the BAK samples we measured water contents between 1 and $30 \%$, but it is possible that samples dried out during transport if sample containers were not completely air tight. Therefore, we use the grain size composition of each sample to estimate a paleo-water content (see Supplement 1, Supplementary Figure 4) of $25 \pm$ $10 \%$ for samples with a fine silt and clay content above $25 \%$ and $15 \pm 10 \%$ for samples below this value.

The fine-grain $(4-11 \mu \mathrm{m})$ pIRIR $_{290}$ and BSL ages of BAK1-1 (8.23 $\mathrm{m}$ depth) and BAK1-2 (7.93 $\mathrm{m}$ depth), which bracket the $\mathrm{CI} / \mathrm{Y}-5$ tephra agree well with its established ${ }^{40} \mathrm{Ar} /{ }^{39} \mathrm{Ar}$ age of $39.85 \pm 0.14 \mathrm{ka}$ (Giaccio et al., 2017), while coarse-grain $(63-90 \mu \mathrm{m})$ pIRIR $_{290}$ ages at $8.23 \mathrm{~m}$ and $7.93 \mathrm{~m}$ depth seem to overestimate the tephra age slightly $(\sim 1 \mathrm{ka}$ when $1 \sigma$ error is considered; Figure 4). The older coarse-grain feldspar ages may be explained by contributions of coarse-grained tephra particles that were not removed completely during sample 


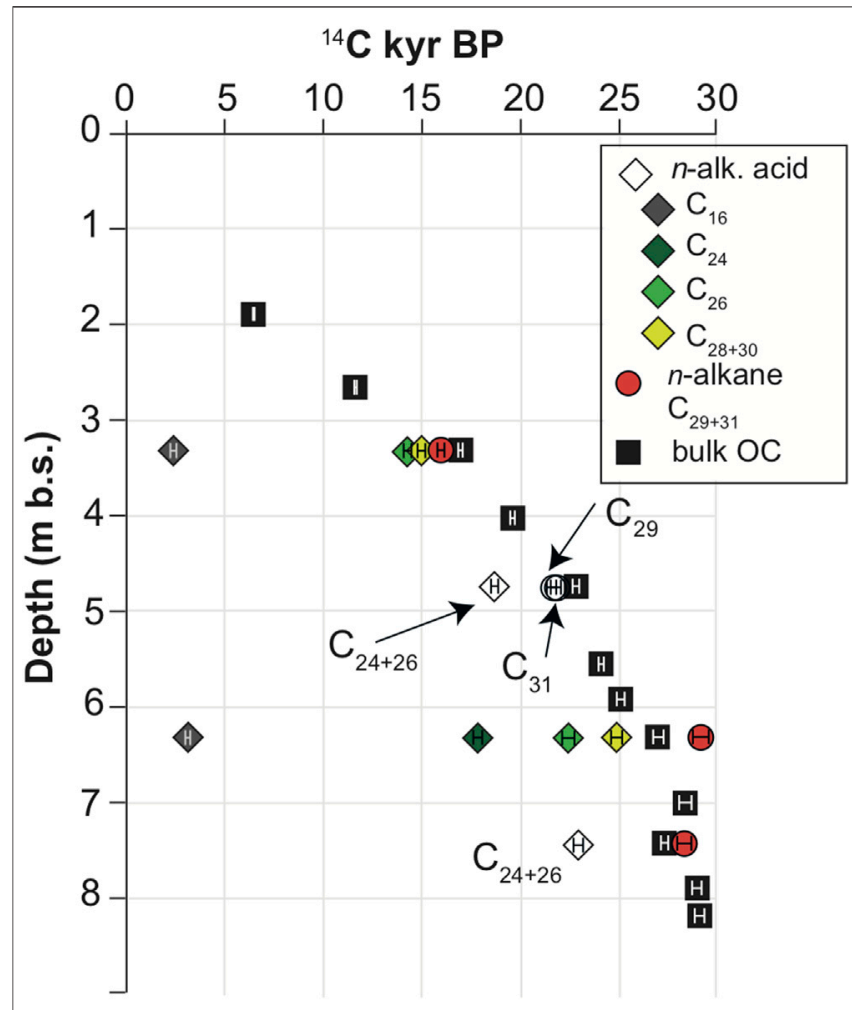

FIGURE 5 | Conventional ${ }^{14} \mathrm{C}$ ages of bulk organic carbon $(\mathrm{OC})$ and of $n$-alkanes and $n$-alkanoic acids versus depth. Symbols include error bars.

preparation. Dating tephra deposits using luminescence techniques is not always straightforward, even when the surrounding sediments are dated (cf. Bösken and Schmidt, 2020). Independent of the dated grain-size range, samples taken in close proximity to the tephra layer are particularly critical, since fresh geologic deposits are prone to relocation of radioelements leading to an incorrect ascertainment of dose rates (Krbetschek et al., 1994; Biswas et al., 2013; Bösken and Schmidt, 2020). In the Middle and Lower Danube Basins, loess layers embedding the CI/ Y-5 tephra have been often dated using luminescence dating methods (Constantin et al., 2012; Fitzsimmons et al., 2013; Veres et al., 2013; Anechitei-Deacu et al., 2014; Bösken et al., 2017; Obreht et al., 2017; Zeeden et al., 2018c): depending on the specific dose rate of the profiles, equivalent doses of loess layers above the CI/Y-5 tephra range from $114 \pm 7$ Gy to $200 \pm 4$ Gy for fine-grained quartz and $104 \pm 6$ Gy to $221 \pm 12$ Gy for fine-grained polymineral pIRIR $_{290}$ measurements, respectively, while values below the tephra layer range from $136 \pm 6 \mathrm{~Gy}$ to $286 \pm 9 \mathrm{~Gy}$ (fine-grained quartz) and from $172 \pm 12$ Gy to $193 \pm 4$ Gy (finegrained polymineral $\mathrm{pIRIR}_{290}$ ), respectively. These values result in ages between 26-44 ka above and 39-57 ka below the tephra. In the $\mathrm{BAK}$ sequence, equivalent doses and ages are in the same age range as reported in those studies. This highlights the consistency of luminescence ages among the BAK site and other loess sites in the region. Given the fact that fine-grain $\mathrm{PIRIR}_{290}$ results seem to provide the most accurate age around the tephra, we only use the fine-grain pIRIR $_{290}$ ages for our integrated age-depth model.

\section{Radiocarbon Analysis}

Sedimentary bulk OC contains a mix of organic matter (OM) from different sources with different ${ }^{14} \mathrm{C}$ isotope signatures that may either be deposited syn-depositionally or introduced postdepositionally. For example, OM reworked from older deposits (e.g., eroded from bedrock or soils in the source area of the dust) may have a ${ }^{14} \mathrm{C}$ isotope signal, which is older than the actual age of loess deposition or potentially radiocarbon-dead. In contrast, OM introduced after sediment deposition, e.g., leaching by percolating pore water, may be younger than the sediment (e.g., Hatté et al., 2001). Typically, aboveground biomass is preferably used for dating terrestrial sediments, since roots can extend up to several meters below the surface introducing modern $\mathrm{C}$ into deeper layers of the loess profile. In addition to macroscopic plant remains, epicuticular leaf wax lipids such as long-chain $n$-alkanes $\left(n-\mathrm{C}_{27}\right.$ to $n$ - $\left.\mathrm{C}_{35}\right)$ and $n$-alkanoic acids $\left(n-\mathrm{C}_{24}\right.$ to $\left.n-\mathrm{C}_{32}\right)$ are preserved in sedimentary records. As done by us in the $\mathrm{BAK}$ profile, these lipids have previously been tested as target OC for loess ${ }^{14} \mathrm{C}$ chronologies (e.g., Häggi et al., 2014; Haas et al., 2017; Zech et al., 2017; Bliedtner et al., 2020). In the following we will discuss to what extent the ${ }^{14} \mathrm{C}$ ages of bulk OC and of leaf wax lipids provide a representative estimate of the actual age of sediment deposition in the BAK profile.

Above $7.05 \mathrm{~m}$ depth, bulk OC ${ }^{14} \mathrm{C}$ ages successively increase with depth, suggesting that bulk OC may provide meaningful age information (Figure 5). Below this depth, ${ }^{14} \mathrm{C}$ ages do not increase continually, which could be due to very high sedimentation rates in this part of the profile. However, an age reversal at $7.47 \mathrm{~m}$ depth indicates that mixing with younger OM (e.g., by bioturbation) likely influences ${ }^{14} \mathrm{C}$ ages in this part of the profile (Figures 2, 5). This interpretation is strongly supported by the presence of the independent age marker (CI/Y-5 tephra layer, $39.85 \pm 0.14 \mathrm{ka})$ at $\sim 8 \mathrm{~m}$ depth, since the calibrated bulk OC ${ }^{14} \mathrm{C}$ age from below this depth yields 32.71-33.87 cal ka BP (Table 2). Analogous to soils, loess deposits are not closed systems and the ${ }^{14} \mathrm{C}$ isotope signature of bulk OC or individual compounds is determined by their intrinsic turnover times determined by input vs. output flux (e.g., Trumbore, 2009). Soils are also prone to physical disturbance such as bioturbation by roots, which penetrate into deeper horizons and admix younger OM into older sediments (e.g., Zech et al., 2017). Similar to leaves, roots contain some proportion of $n$-alkanoic acids, with dominance of the $n-C_{24}$ homolog (e.g., Wiesenberg et al., 2012). In the BAK profile, $n-\mathrm{C}_{24}$ alkanoic acid is less ${ }^{14} \mathrm{C}$-depleted than bulk OC, suggesting the presence of "younger" root-derived material in the older BAK sediments (Figure 5). Evidence for admixture of younger OC throughout the loess sequence also comes from the two ${ }^{14} \mathrm{C}$ ages obtained on $n-\mathrm{C}_{16}$ alkanoic acids from 3.35 and $6.35 \mathrm{~m}$ depth. Both alkanoic acids are significantly younger than the other analyzed OC fractions from the same sediment samples with offsets of $>25 \mathrm{kyr}$. Short-chain $n-\mathrm{C}_{16}$ and $n-\mathrm{C}_{18}$ alkanoic acids are produced by plants (leaves and roots, e.g., Wiesenberg et al., 2012) but also derive from microbial sources (e.g., phospholipid $n$-alkanoic acids in soils; Zelles, 1999). Admixture of OC from roots and microbes with "younger" ${ }^{14} \mathrm{C}$ isotope signatures has particularly large effects on 
relatively old samples and likely limits the applicability of bulk OC ${ }^{14} \mathrm{C}$ dating in loess deposits to sediments $<25{ }^{14} \mathrm{C} \mathrm{ka}$, which per mass balance are less biased by such contributions. Similar results from LPS sequences in Central Asia (Song et al., 2018b) indicate that this is likely characteristic for LPS deposits in general and not a feature inherent to the BAK site.

For dating loess deposits, OM sub-pools that are less prone to admixture of younger material, likely provide a more accurate age assignment. The ${ }^{14} \mathrm{C}$ ages of the other epicuticular leaf wax lipids in BAK sediments are older than the age of the $n-\mathrm{C}_{24}$ alkanoic acid (Figure 5), with $n-\mathrm{C}_{29}$ and $n-\mathrm{C}_{31}$ alkanes consistently providing the oldest ages and being in good agreement with bulk OC ${ }^{14} \mathrm{C}$ ages. However, the systematic depletion in ${ }^{14} \mathrm{C}$ of $n-\mathrm{C}_{29}$ and $n-\mathrm{C}_{31}$ alkanes relative to the corresponding $n-\mathrm{C}_{28+30}$ alkanoic acids in all investigated samples indicates that different biogeochemical processes affect ${ }^{14} \mathrm{C}$ signatures of individual compounds and compound classes. The $n$-alkanoic acids show a systematic increase in age with increasing chain length (Figure 5), an observation that is well known from marine sediments (e.g., Kusch et al., 2010), but data from soils are limited (van der Voort et al., 2017). In addition to compound source variability, this observation is also considered an effect of selective degradation leading to relative ${ }^{14} \mathrm{C}$ enrichment of the short-chain $n$-alkanoic acid pool relative to the long-chain homologs (e.g., Matsumoto et al., 2007). The older ages of long-chain $n$-alkanoic acids relative to short-chain $n$-alkanoic acids as well as $n$-alkanes relative to long-chain $n$-alkanoic acids likely also reflect a fast turnover of short-chain $n$-alkanoic acids and slow turnover of $n$-alkanes in the loess (e.g., Wiesenberg et al., 2008; van der Voort et al., 2017). In addition, $n$-alkanes in sediments may also contain some proportion derived from geological ( ${ }^{14} \mathrm{C}$-free) sources resulting in bias towards ${ }^{14} \mathrm{C}$ ages that are older than the actual sedimentation age (e.g., Bliedtner et al., 2020). In subsection BAK1, however, the chain lengths distribution of $n$-alkanes is similar to that found in grasses and herbs implying negligible contribution of $n$-alkanes from petrogenic sources (cf. Supplement 2). In summary, $n$-alkane ages closely correspond to bulk OC ${ }^{14} \mathrm{C}$ ages and we conclude that both $n$-alkanes and bulk OC reflect the best sediment age estimates in this study. For the age-depth model we therefore use $n$-alkanes and bulk OC ${ }^{14} \mathrm{C}$ ages. However, ${ }^{14} \mathrm{C}$ ages from $7.05 \mathrm{~m}$ depth and below are not considered in age-depth modeling, since these ages are biased by admixture of "younger" OC resulting in significant underestimation of actual sedimentation ages.

\section{Magnetic Stratigraphy}

The paleomagnetic chronostratigraphic framework for the BAK pmag composite profile is essentially based on the correlation of the smoothed RPI values with the GLOPIS-GICC05 data set. The RPI of loess sequences is not widely used for age determination even though a number of studies gained reasonable results (e.g., Liu et al., 2005; Zeeden et al., 2009; Rolf et al., 2014; Li et al., 2020). At the BAK site, the basic requirement of homogeneity of magnetic properties is fulfilled as shown in the mineral magnetic assessment (Supplementary Section 3.3). The BAK
TABLE 3 | Tie points of RPI correlation (1-6, cf. Figure 6) assigned to the ages resulting from correlation with GLOPIS-GICC05. Tie points resulting from correlation of magnetic susceptibility data (A-H, cf. Figure 6) are shown as mean ages and their age variation. These values do not represent confidence intervals.

\begin{tabular}{|c|c|c|}
\hline \multirow[t]{2}{*}{ Tie point } & Depth & Age \\
\hline & (m b.s.) & (ka) \\
\hline 1 & 5.83 & 26.08 \\
\hline 2 & 6.51 & 31.73 \\
\hline 3 & 7.39 & 35.76 \\
\hline 4 & 8.22 & 40.97 \\
\hline 5 & 8.67 & 43.63 \\
\hline 6 & 9.59 & 51.92 \\
\hline A & 5.83 & $25.84 \pm 0.65$ \\
\hline B & 6.17 & $27.63 \pm 0.11$ \\
\hline C & 6.39 & $28.71 \pm 0.09$ \\
\hline D & 7.11 & $32.80 \pm 0.08$ \\
\hline$E$ & 7.61 & $35.88 \pm 0.02$ \\
\hline $\mathrm{F}$ & 8.55 & $43.43 \pm 0.89$ \\
\hline G & 9.36 & $47.75 \pm 0.92$ \\
\hline $\mathrm{H}$ & 9.75 & $53.99 \pm 0.01$ \\
\hline
\end{tabular}

pmag composite and GLOPIS-GICC05 show greater similarities in the upper than in the lower part, but allow for correlation of significant features in both cases (Figure 6). However, various confounding factors introduce uncertainties when aligning different records. The record of the past variability of the intensity and direction of the Earth's magnetic field in sediments depends to a large extent on the accumulation rate and the complex remanence acquisition processes. Additionally, hiatuses, bioturbation and chemical overprinting may influence the record (Evans and Heller, 2001; Roberts and Winklhofer, 2004; Jin and Liu, 2010). Therefore, not all highs and lows of the RPI reference record may be similarly expressed in the BAK profile. In fact, only when considering the stratigraphic position and age of the CI/Y-5 tephra layer, six tie points (1-6, Table 3) can be determined for visual correlation of the two RPI records (Figure 6). Additional tie points would be ambiguous. Thus, we limit the number of tie points, but acknowledge that this approach may average out possible variations in accumulation rate. The age-depth data resulting from the correlation (Table 3) imply that the BAK pmag composite profile comprises two magnetic excursions, Mono Lake and Laschamp. The Mono Lake excursion (Channell et al., 2020) may correspond to the RPI low in the BAK profile between tie points 2 and 3 (Figure 6). We decided not to tie this RPI low to the GLOPIS-GICC05 curve, because the sections above and below would be substantially stretched and clinched, respectively. It is still under debate whether the Mono Lake geomagnetic excursion occurs globally synchronous, asynchronous, or may be a series of excursions across a given time interval (Korte et al., 2019). From the correlation applied in Figure 6, the putative Mono Lake excursion is dated at $33.2 \mathrm{ka} \mathrm{BP}$. Despite the offset to the Mono Lake excursion in GLOPIS-GICC05, dated at $34.15 \mathrm{ka}$ $\mathrm{BP}$, it is within the time interval associated with the excursion in other parts of the world (Channell et al., 2020). The second geomagnetic excursion is the Laschamp with an age of $\sim 41 \mathrm{ka}$ (Channell et al., 2020). It is recorded only as a minor decrease of 
the RPI in the BAK composite, but is supported by the stratigraphic position just below the CI/Y-5 tephra layer (Figure 6). Thus, this excursion defines tie point $4(8.22 \mathrm{~m})$. Using this tie point, the BAK record can be directly linked to the RPI record of Poiana Ciresului. However, even though Mono Lake and Laschamp can be distinguished at the Poiana Ciresului site (Zeeden et al., 2009), the magnetic record is partly corrupted due to the high number of archeological layers (Nițu et al., 2019) and a visual side-by-side comparison is difficult. Because the RPI record of the Poiana Ciresului site does not extend below the Laschamp geomagnetic excursion, a comparison with BAK is not possible for the complete BAK pmag composite profile. In the lowermost part of the BAK pmag composite, the RPI record shows a similar trend matching two different sections of the GLOPIS-GICC05 record, i.e., at $51.9 \mathrm{ka}$ and $46.9 \mathrm{ka}$. Considering the thickness of the BAK LPS and the lack of macroscopic evidence suggesting an increase of the accumulation rate such as sandy layers or a general increase in grain size, we tentatively

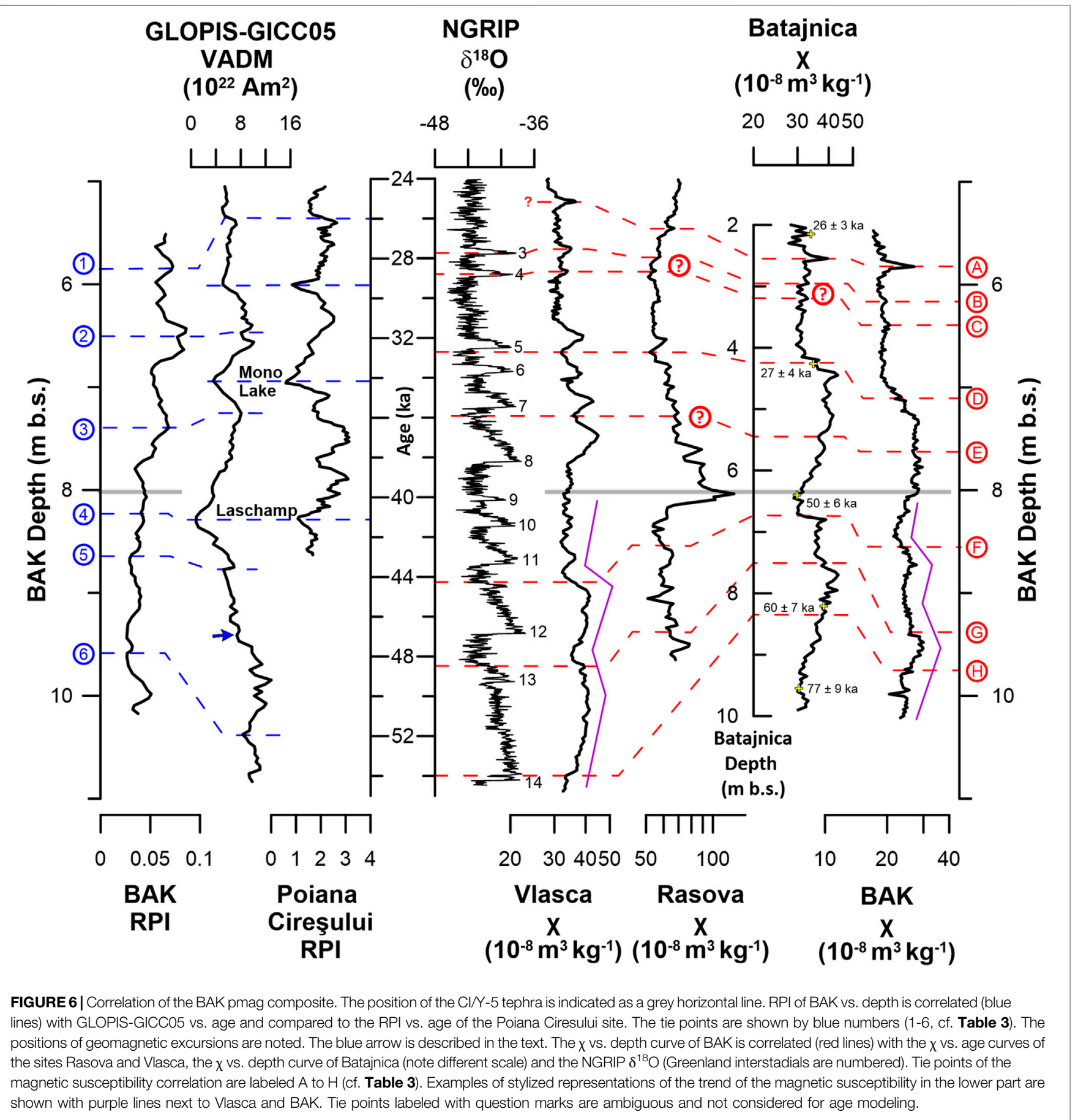


favor the correlation that leads to an age of $51.9 \mathrm{ka}$ instead of 46.9 ka (blue arrow in Figure 6). This solution results in a moderate decrease of accumulation that could be explained by hiatuses, while the alternative would require a sudden and extreme increase of sediment deposition rates.

The second magnetic dating approach is based on correlation of the magnetic susceptibility. This technique was first proven to be useful by Heller and Liu (1986) and is widely applied since then. We correlate eight tie points of the magnetic susceptibility curve of the BAK pmag composite profile (labeled A to $\mathrm{H}$ from top to bottom) to selected loess records of the region (Figure 6), as well as to the NGRIP $\delta{ }^{18} \mathrm{O}$ isotope record. The ages obtained using this method depend either on the age models of the reference records or the relationship of the fluctuations of the magnetic susceptibility to the interplay of interstadial-stadial events expressed in the NGRIP record. In both cases, the results should only be used with caution. On the one hand, the age models of the selected loess records are partly compiled from multiple dating approaches, including radiocarbon and luminescence dating (Supplementary Table 3). Given that we also aim at testing the feasibility of different dating methods, the use of these data may result in a vicious circle. On the other hand, the magnetic susceptibility is biased by non-climatic factors such as grain-size distribution and local dust influx. The characteristic features of the magnetic susceptibility curve of a section may therefore not coincide with those of the NGRIP record, although they may look similar. Furthermore, a delayed response of the loess properties to climate change may have occurred (Ujjári et al., 2014a). Nevertheless, we apply the correlation of the magnetic susceptibility in order to provide a comparison to the RPI derived age model.

Tie point A $(5.83 \mathrm{~m})$ is a characteristic peak that is recognized in all reference records (Figure 6). At the BAK site, it is a horizon rich in organic matter, which could be a small pedogenic horizon. Because of its thinness, it might be a short-term regional signal; thus, we did not correlate the peak to the NGRIP record. The small peaks defined as tie points $\mathrm{B}(6.17 \mathrm{~m})$ and $\mathrm{C}(6.39 \mathrm{~m})$ correspond to Greenland interstadials (GI) 3 and 4 in the NGRIP curve. They are also easily identified in the magnetic susceptibility curve of Vlasca, but not unequivocally recognizable at Batajnica and Rasova. In contrast, tie points $\mathrm{D}(7.11 \mathrm{~m})$ and $\mathrm{E}(7.61 \mathrm{~m})$ are based on a striking resemblance of the shape of the BAK curve with Batajnica. The further correlation of $\mathrm{D}$ is based on the correlation of Batajnica with Rasova, which show clear similarities in the range between $\mathrm{C}$ and $\mathrm{D}$. By comparison, the Vlasca record shows higher similarity to the NGRIP curve than to the BAK curve. However, the position of $\mathrm{E}$ in Batajnica can be correlated very well with Vlasca. The identification of tie point $\mathrm{E}$ in the Rasova profile is more complicated since characteristic features are missing.

The CI/Y-5 tephra is found between tie points $\mathrm{E}$ and $\mathrm{F}$ $(8.55 \mathrm{~m})$ in the BAK, Vlasca and Rasova profiles. The correlation of the curves in the profile section below this marker horizon is less obvious than above, which might be due to regional differences in the intensity of pedogenetic overprinting. A general trend consisting of multiple changes between moderate decreases and fast increases of the magnetic susceptibility towards larger depth can be recognized more or less clearly in all magnetic susceptibility records. Stylized representations of this trend are visualized with purple lines along the Vlasca and BAK curves in Figure 6. Based on this observation, the tie points $\mathrm{F}, \mathrm{G}(9.36 \mathrm{~m})$ and $\mathrm{H}(9.75 \mathrm{~m})$ are defined. $F$ and $G$ are located within an increase of magnetic susceptibility, $\mathrm{H}$ is positioned in a small minimum above a stronger decrease of magnetic susceptibility, which is interpreted to reflect the beginning of GI 14. It should be noted from the tie lines that the age model resulting from the correlation of the site Rasova with NGRIP (Zeeden et al., 2016; Zeeden et al., 2018c; Zeeden et al., 2019) is different to the correlation we suggest in this study. Accordingly, the positions of the tie point within the Rasova record provide minimum age estimates for the magnetic susceptibility age model of BAK. In contrast, the polymineral pIRIR 225 ages of Batajnica in this part of the section appear slightly too old (shown in Figure 6) and will not be further discussed in this study.

The BAK age models derived from correlation of RPI and magnetic susceptibility include all tie points (Figure 7) that are not denoted with a question mark in Figure 6. All used tie points are equally weighted and considered in the integrating age model (Integrating Age Models). According to the age models based on magnetic susceptibility and RPI correlation, the sediment at the depth of the CI/Y-5 tephra was deposited 39.3 and $40.6 \mathrm{kyr}$ ago, respectively. Due to the good agreement with the known age of $39.85 \pm 0.14 \mathrm{ka}$ (Giaccio et al., 2017), the models appear robust. Overall the models resulting from magnetic dating agree well. In the upper part, the age models diverge slightly, because tie points $\mathrm{C}, \mathrm{D}$ and $\mathrm{E}$ do not correspond to tie points 2 and 3 . As a consequence, the age models shift between 5.8 and $8.2 \mathrm{~m}$ depth with a maximum age offset of $2.3 \mathrm{ka}$. In general, ages that are younger than expected might be explained (to a certain degree) by a lock-in effect, which causes the sediment to carry the magnetic signal of a younger time interval than that of sediment deposition. The lock-in depths of paleomagnetic signals in LPSs strongly depend on the syn-depositional water availability as well as at the degree of diagenesis and pedogenesis (e.g., Liu et al., 2015) and are therefore difficult to estimate. However, the BAK profile is characterized by good preservation of subtle sedimentological structures such as the CI/Y-5 tephra layer and macroscopically visible layers of fine sands within unaltered loess as well as in interstadial soils. Thus, an overprinting of the primary depositional signal by postdepositional processes (bioturbation, pedogenesis) seems minimal. A conservative estimate of the potential temporal offset can be calculated assuming a lock-in depth of $0.1-0.15 \mathrm{~m}$ in unaltered loess and a slightly higher lock-in depth in interstadial soils. This leads to a potential temporal offset of $\sim 1 \mathrm{kyr}$ for the average accumulation rate of the BAK pmag composite profile. However, the ages resulting from RPI correlation, which are also based on the magnetic properties, exclude a significant bias from a lock-in effect. Thus, the age discrepancies may rather arise from a mismatch during correlation. In the lower part of the BAK profile, tie point $G$ causes a different shape of the age-depth plot of the susceptibility/ NGRIP based model (Figure 7). This difference can be explained 
by the different frequency of tie points. Irrespective, the age constraints provided by the magnetic stratigraphy approaches overall suggest rather consistent accumulation rates over time.

\section{Integrating Age Models}

Age-depth models are used for constraining the chronological age assuming that samples in stratigraphic order must have chronological order (e.g., Buck et al., 1996; Bronk Ramsey, 2009). Age-depth modeling generally allows for reducing uncertainty of the age estimates when uncertainties of individual ages overlap. This approach has been previously employed to loess deposits in the Danube catchment (e.g., Fenn et al., 2020a; Fenn et al., 2020b; Sümegi et al., 2020). In this study, we select the most accurate ages obtained with each method for age-depth modeling (for details see discussion of individual methods). Hence, age information for the upper half of the BAK profile is provided by ${ }^{14} \mathrm{C}$ data, while the lower part is covered by results of luminescence dating and magnetic stratigraphy (Figure 8A). Unfortunately, while we were aiming at high data coverage allowing cross-method validation, robust OSL and radiocarbon ages overlap only at 5.59 and $6.35 \mathrm{~m}$ depth.

We apply two age-depth models, one of which is conservative in reducing uncertainty (ADMin; Figure 8C) and the other interpolates ages between the dated horizons (BChron; Figure 8B). Both models use ages and their respective 2-sigma uncertainty. We compare the model outputs in a similar fashion as the data to discuss the chronology of the BAK profile using dating and modeling approaches; model output is available in the supplementary materials (Supplementary Tables 8-10). The BChron model (Figure 8B) shows an age span of $\sim 6$ to $\sim 54 \mathrm{ka}$ BP for the uppermost $9-10 \mathrm{~m}$ of the BAK profile. In the upper half of the profile, the sedimentation model produces increasing uncertainties between individual ages. This is due to relatively few age control points in this section and the gammadistribution based sedimentation model inherent to this method. At $\sim 6 \mathrm{~m}$ depth, the model is clearly constrained by the ${ }^{14} \mathrm{C}$ ages and uncertainty is confined by the high precision of the ${ }^{14} \mathrm{C}$ ages. Around the CI/Y-5, uncertainty is strongly reduced by this welldated marker bed. For the oldest three samples, the model provides the best fit using the younger ages included in the $95 \%$ uncertainty interval. This is probably due to the sedimentation model, which forces the results towards a constant accumulation rate. The ADMin model (Figure 8C) does not interpolate ages, but only produces model ages for dated depths. Up to $\sim 5.5 \mathrm{~m}$ depth, both the BChron and the ADMin model results are similar; below this depth, the ADMin model results include higher uncertainty between several ${ }^{14} \mathrm{C}$ dated layers at $\sim 6 \mathrm{~m}$ depth. In general, since the random portion (not shared portion) of uncertainty is used in the model, it reduces the uncertainty of the age model less. In this study, the random component makes up an average of about $60 \%$. Analogous to BChron, the ADMin age models best fit is shifted towards younger ages for the lowermost three ages, but not as much as the BChron model.

Overall, the BChron and the ADMin models are in good agreement (Figure 8D). The age-depth models based on magnetic and luminescence data are in excellent agreement and are supported by the age of the CI/Y-5 tephra. Both models have their strengths. The BChron model interpolates ages and directly constructs a chronology for the whole sedimentary sequence. The ADMin model deliberately does not do this to avoid potential incorrect interpolation (cf. Telford et al., 2004; Trachsel and Telford, 2017). Because of their similarity we do not consider one model better than the other. Further constraints of the BChron and ADMin Bayesian models are based on a suite of assumptions about the sedimentation process itself and on the correctness of both ages and uncertainties. The uncertainties of magnetic and luminescence ages may be over- or underestimated, which may influence the age-depth models. Especially for magnetic dating, uncertainties are not easy to calculate, since they include uncertainties that are associated with each stage of paleomagnetic analysis (Tauxe et al., 2010; Heslop and Roberts, 2020). In case of the magnetic data set of the BAK site, we only estimate uncertainty, i.e., we have a component of random uncertainty (e.g., through proxy data) and also systematic effects from correlation with a possibly biased reference chronology. We acknowledge that such an uncertainty should not be used for modeling per se (Zeeden et al., 2018c), but in the absence of alternative quantifiable methods this is a common approach. In this case, we argue that the mean modeled age should be correct within $\sim \pm 10 \%$ of the real age, because this would account for

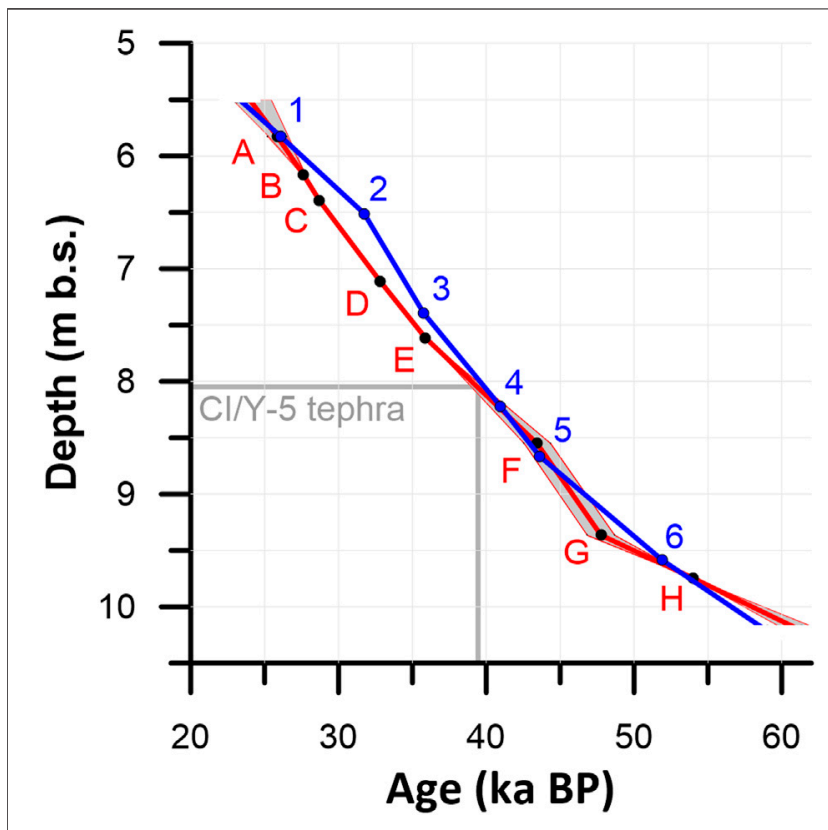

FIGURE 7 | Age models derived from RPI (blue) and magnetic susceptibility/NGRIP correlation (red). Because different ages arise from the correlation of most tie points by magnetic susceptibility correlation, the mean value is given by the red line framed by a shaded area confined by the minimum and maximum ages. This area does not represent the confidence interval. The tephra layer is indicated in grey at $39.85 \mathrm{ka}$ (Giaccio et al., 2017). 

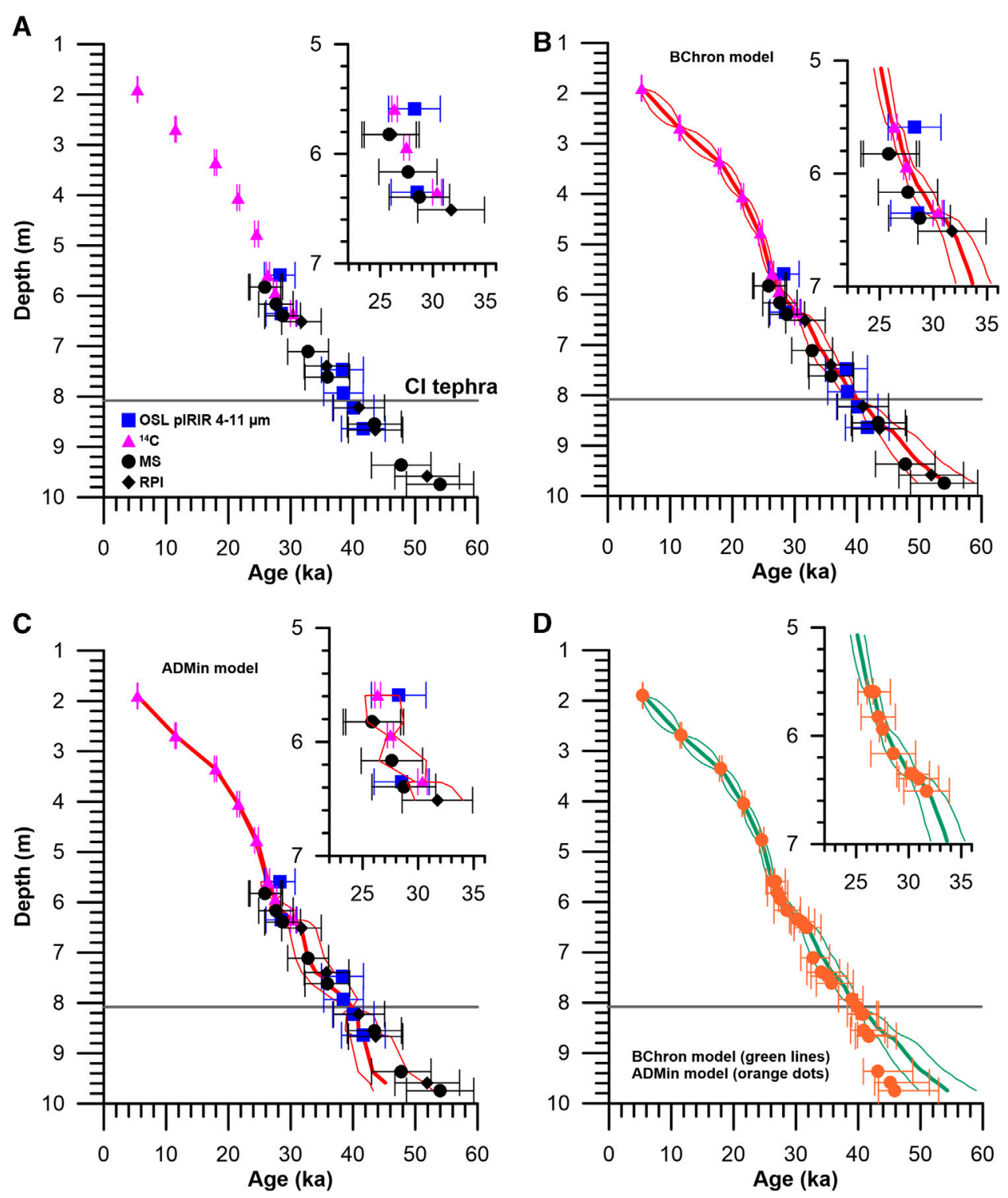

FIGURE 8| Age models for the BAK profile. The legend is included in (A). (A) Cross plot of age vs. depth used for modeling, where calibrated ${ }^{14} \mathrm{C}$ ages and OSL ages (pIRIR 4-11 $\mu \mathrm{m}$ ) are given as magenta triangles and blue squares, respectively. For several depths $(3.35 \mathrm{~m}, 4.77 \mathrm{~m}, 6.35 \mathrm{~m})$, all reliable ${ }^{14} \mathrm{C}$ ages were calibrated and then averaged. Ages obtained by magnetic stratigraphy (black) distinguish between magnetic susceptibility-based data (circles) and RPI based data (diamonds). (B) The result of the BChron model including a 95\% confidence interval. (C) The results of the ADMin model including a 95\% confidence interval. (D) Comparison of results from the ADMin (orange) and Bchron (green) models. The uncertainty range of the BChron model is shown as green circles to facilitate comparison. Note that these are in very good agreement in the upper part, but deviate below $\sim 5.5 \mathrm{~m}$ depth. For clarity, the insets show a close-up of the data around $6 \mathrm{~m}$ depth.

possibly systematic parts of uncertainty and possibly uncertainty sources which were not accounted for by radiometric dating. Another problem is the confined uncertainty at $\sim 6 \mathrm{~m}$ depth with an age of $\sim 30 \mathrm{ka}$, which may not be a realistic model outcome as it relies on the assumption that the ${ }^{14} \mathrm{C}$ age is unambiguous. Finally, due to the good agreement of the BChron and ADMin age models, we do not favor one model over the other. In both models, the composite section of the BAK LPS analyzed in this study comprises an age of $\sim 56 \mathrm{ka}$ (with a difference of $\sim 2 \mathrm{ka}$ ). The age-depth trend reflects semi-constant sediment accumulation similar to existing records from the region (e.g., Tecsa et al., 2020; Zeeden et al., 2020).

\section{Evaluation of the Multi-Method Approach and Implications for Future Studies}

Most studies of LPSs combine OSL dating with either ${ }^{14} \mathrm{C}$ analysis or magnetic stratigraphy to gain age control (e.g., Novothny et al., 2011; Song et al., 2012; Újvári et al., 2014a; Újvári et al., 2014b; Song et al., 2015; Song et al., 2018b; Zhang et al., 2018), while a 
combination of ${ }^{14} \mathrm{C}$ analysis and magnetic stratigraphy is less commonly used (Zeeden et al., 2011). Only in a very few cases all three methods have been applied in concert (e.g., Zeeden et al., 2009; Li et al., 2020). However, none of these studies compared the results of different dating approaches systematically against each other or investigated the effects of age-depth models. In this respect, we provide a unique case study for comparison and integration of the three dating methods most commonly used in loess research. Above, we illustrate that each of the methods provides reasonable age constraints, even though all individually are subject to method-specific biases and limitations. In the following, we compare the results of the BAK section between $\sim 5.6$ and $\sim 8.7 \mathrm{~m}$ depth in a stratigraphic context to evaluate the multi-method approach. To allow us to directly compare magnetic stratigraphy at those depths constrained by luminescence and/or radiocarbon ages, we use linear interpolation between tie points (the respective age values are marked with an asterix).

The ages obtained using the different methods show a considerable spread of up to $\sim 15 \mathrm{ka}$ at $6.35 \mathrm{~m}$ depth and $>25 \mathrm{ka}$ at $7.47 \mathrm{~m}$ depth (Figure 9). However, some ${ }^{14} \mathrm{C}$ and OSL ages were identified to be biased by post-depositional processes ( $n$-alkanoic acids with chain lengths <28) and uncertainty in the correction procedure for anomalous fading $\left(\mathrm{IR}_{50} 4-11 \mu \mathrm{m}\right.$ and $\left.63-90 \mu \mathrm{m}\right)$ and will, thus, not be discussed further. Ages obtained by $\mathrm{IR}_{50}$ deviate substantially from the age constraints provided by magnetic stratigraphy, radiocarbon chronology and the other OSL ages (Figure 9). This indicates that $\mathrm{IR}_{50}$ measurements are less suitable for many geochronological questions - at least at the BAK LPS - due to reduced accuracy. The remainder of the data cluster in variable groups over depth. At $5.59 \mathrm{~m}$ depth, bulk OC ${ }^{14} \mathrm{C}$ and OSL (pIRIR $\left._{290} 4-11 \mu \mathrm{m}\right)$ ages are in very good agreement $(29.9 \pm$ $0.7 \mathrm{ka}$ and $28.2 \pm 2.5 \mathrm{ka}$, respectively). The $\operatorname{pIRIR}_{290}(4-11 \mu \mathrm{m})$ protocol was identified as the most reliable OSL protocol for this profile (setting), which is supported by the overlap with bulk OC ${ }^{14} \mathrm{C}$ ages. In contrast, the results of magnetic stratigraphy seem to be too young in the uppermost section. Down to $6.35 \mathrm{~m}$ depth, the magnetic stratigraphy correlation shows an offset of $\sim 2,000$ years relative to the bulk $\mathrm{OC}{ }^{14} \mathrm{C}$ ages. At $6.35 \mathrm{~m}$ depth, OSL (pIRIR $2904-11 \mu \mathrm{m})$ and ${ }^{14} \mathrm{C}\left(n-\mathrm{C}_{28+30}\right.$ alkanoic acids) ages as well as magnetic stratigraphy correlation $\left(28.5^{\star} \mathrm{ka}\right)$ range between $28.5 \pm 2.5 \mathrm{ka}$ and $30.6 \pm 0.7 \mathrm{ka}$, while OSL (BSL $4-11 \mu \mathrm{m}),{ }^{14} \mathrm{C}$ (bulk OC and $n$-alkanes) and RPI correlation $\left(30.4^{\star} \mathrm{ka}\right)$ age estimates range between $30.3 \pm$ $3.2 \mathrm{ka}$ and $32.3 \pm 1.8 \mathrm{ka}$. Because the latter group includes those ages identified as the most accurate for ${ }^{14} \mathrm{C}$ and magnetic stratigraphy and we regard BSL and PIRIR as equally suitable we favor the older age assignment here. Although the bulk OC ${ }^{14} \mathrm{C}$ age at $7.05 \mathrm{~m}$ depth $(32 \pm 0.8 \mathrm{ka})$ is in very good agreement with the age obtained by magnetic stratigraphy correlation $\left(31.7^{\star} \mathrm{ka}\right)$, it probably underestimates the sedimentation age due to the contribution of younger $\mathrm{OC}$ from overlying strata or roots. A bias towards young ${ }^{14} \mathrm{C}$ ages is also evident for the section below implying that ${ }^{14} \mathrm{C}$ ages do not reliably reflect sediment ages older than $\sim 30-32 \mathrm{ka} \mathrm{BP}$ in the BAK section. As a consequence, the age of magnetic stratigraphy tie point $\mathrm{D}(7.11 \mathrm{~m})$ is likely also too young. In contrast, the RPI correlation shows a better fit with the overall trend and likely provides appropriate results. At $7.47 \mathrm{~m}$ depth and below, the ages obtained by $\operatorname{PIRIR}_{290}(4-11 \mu \mathrm{m})$, BSL $(4-11 \mu \mathrm{m})$ and magnetic stratigraphy overlap within the analytical uncertainty of the OSL ages. In contrast, the coarse-grain pIRIR $_{290}$ ages seem to overestimate the time of deposition at the BAK site. Around $8 \mathrm{~m}$, the presence of the CI/Y-5 tephra supports the ages obtained by OSL and the magnetic susceptibility based magnetic stratigraphy. Please note that the RPI based magnetic stratigraphy uses the tephra to adjust the complete correlation; thus, we cannot conclude that the tephra supports the RPI based ages.

Direct comparison of the methods allows us to discern details that otherwise may not be recognized. The consistent results of certain OSL ages with the ${ }^{14} \mathrm{C}$ results and magnetic stratigraphy reveal that OSL may provide accurate ages if a suitable measurement protocol is chosen. As shown above, we suggest to refrain from using the conventional $\mathrm{IR}_{50}$ protocol as this might lead to less precise ages. In future studies, we suggest comparing at least two different luminescence protocols and/or grain-size fractions. It might also be interesting to further investigate coarse-grain feldspar and single-grain measurements. Our ${ }^{14} \mathrm{C}$ analyses of bulk OC and leaf wax lipids support previous findings that show biogeochemical processes inherent to loess deposits may bias bulk or molecular level ${ }^{14} \mathrm{C}$ ages. For this specific LPS profile we conclude that sediments can be reliably ${ }^{14} \mathrm{C}$-dated up to a maximal age of $30 \mathrm{ka}$. This age limit may be higher or lower in other LPS, depending on the proportion of younger (e.g., root-derived) OM relative to contemporaneous OM. With respect to magnetic stratigraphy, both magnetic susceptibility and RPI correlations seem to result in valuable age constraints. Whether preference should be given to one of these methods in future studies, depends on the aim of the study. It has been shown that the correlation to $\delta^{18} \mathrm{O}$ isotope records such as NGRIP alone can be quite complicated and that comparison with local records helps determining tie points. Thus, if additional records from the region are available, the use of magnetic susceptibility is less time-consuming when establishing chronologies. However, a higher availability of RPI and directional data of LPSs is desirable. The RPI would enable deducing the regional field behavior of the Earth's magnetic field and the directional data could potentially provide an additional tool for correlation. Finally, we recommend the use of a carefully selected modeling approach that fits both the specific conditions for a given site and the specific age data generated by the chosen methods. However, we do not advise a specific modeling approach, since the model selection criteria are typically subjective.

The overall good agreement of the individual age data obtained with different methods at BAK is a rare observation in LPS studies and highlights the significance of the study (cf. Li et al., 2020). Especially the use of the tephra in the BAK profile offered the unique possibility of comparing the dating methods against a well-defined time marker. We propose to use this approach in other geochronological 


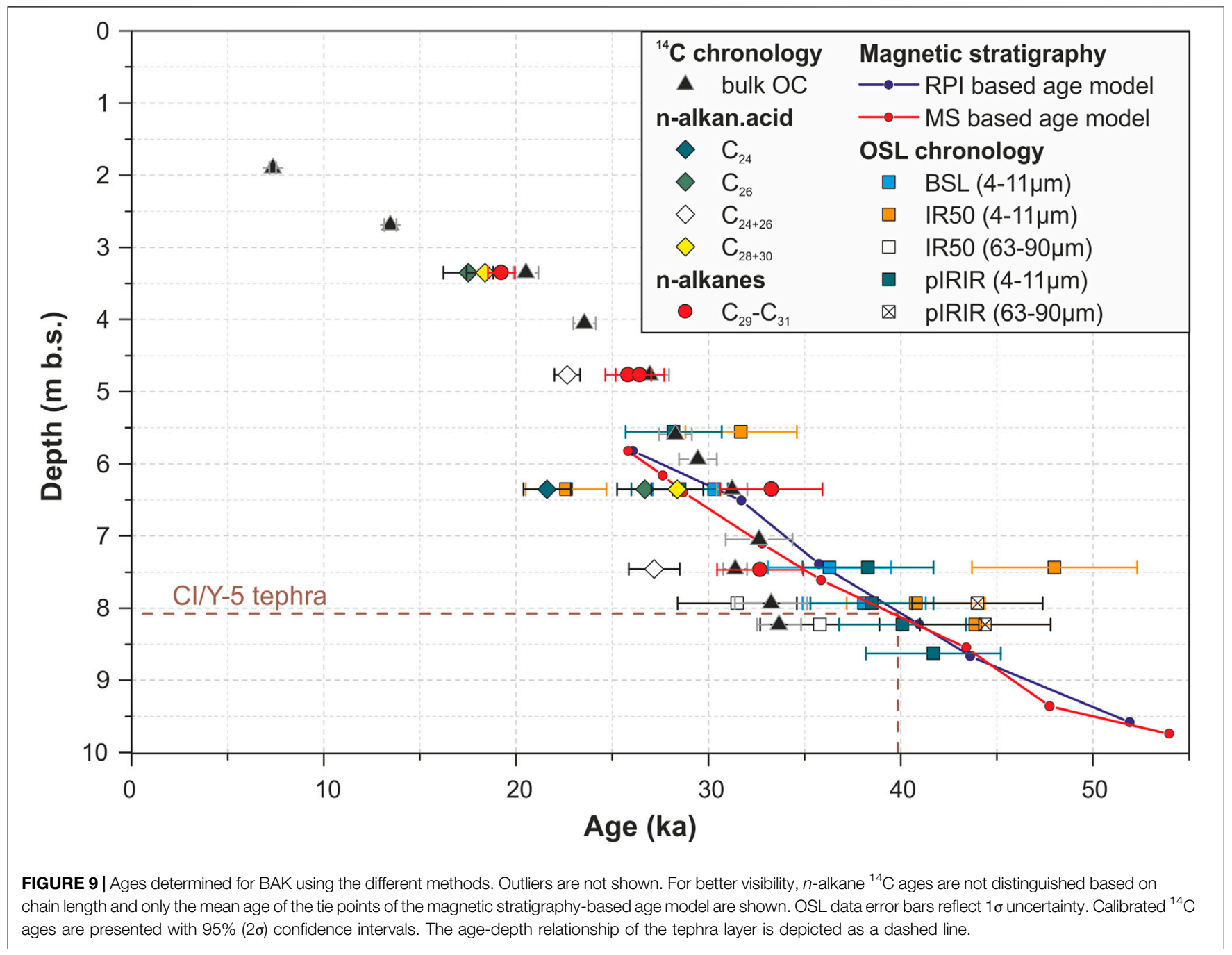

studies that test dating methods against each other. The results highlight that ages from LPSs should be obtained using at least two independent yet complementary dating methods to allow verification of individual results. However, higher data density and age validation using additional techniques seem to substantially increase the reliability of LPS age models. The increased accuracy of the BAK age-depth models may enable correlation of BAK paleoclimatic proxy information to archives with better age control such as speleothems, marine sediments or ice cores (e.g., Svensson et al., 2008; Govin et al., 2015; Staubwasser et al., 2018; Zhang et al., 2019). At best, a resolution beyond the capability of the discussed methods may be achieved, which may in turn allow comparison of paleoclimate trends across regions and archives. This work may assist future studies to find a suitable combination of dating methods and special techniques to obtain accurate and precise chronologies for loess-paleosol sequences. Due to the variability of LPS (e.g., differences in lithology, grain sizes, carbon contents, mineral compositions, vegetation influences), it remains to be tested whether our conclusions regarding the applicability of each method in the BAK profile can be transferred to other LPSs. We regard our current study as a first step to a generalization to facilitate obtaining high quality age models for LPSs.

\section{DATA AVAILABILITY STATEMENT}

All ${ }^{14} \mathrm{C}$ datasets presented in this study are included in the article and the Supplementary Material and are also uploaded in the PANGAEA data repository (Berg, 2020). The data sets of OSL (i.e., DRAC files for age calculation) are available in the CRC806 database (Nett et al. 2020). The magnetic stratigraphy data sets generated for this study are available in the PANGAEA data repository (Scheidt et al., 2020) and in the data repository of the CRC 806. The raw data of the mineral magnetic analyses supporting the conclusions of this article and the data of the sites Vlasca, Batajnica, Poiana Ciresului will be made available by the authors, without undue reservation. 


\section{AUTHOR CONTRIBUTIONS}

$\mathrm{DB}, \mathrm{HB}, \mathrm{FL}, \mathrm{NK}, \mathrm{MM}$ and JR initialized the project. NK suggested the study. UH, JN, DV suggested the site and the investigation approach. SS coordinated the work at the manuscript. JN provided the OSL part, with help from NK, DB, HB, LO: JN (sampling, data interpretation, writing), NK (measurements, data interpretation, writing), DB (review and editing), HB (review and editing), LO (sample preparation, measurements, review and editing). SB provided the ${ }^{14} \mathrm{C}$ part with help from AS, SK, JR: SB (data interpretation, writing), AS (measurements, data interpretation, writing), SK (data interpretation, review and editing), JR (data interpretation, review and editing). SS provided the magnetic stratigraphy part with help from UH, CL, FM: SS (sampling, measurements, data interpretation, writing), UH (sampling, data interpretation, review and editing), CL (measurements, review and editing), FM (Master's thesis: measurements, preliminary data interpretation; review and editing). DV provided the tephrochronology part with help of UH: DV (data interpretation, writing), $\mathrm{UH}$ (measurements, review and editing). $\mathrm{CZ}$ provided the age modeling (calculation, interpretation, writing). SP provided the regional information with help of FL, MM: SP (sampling, field survey, interpretation, writing), FL and MM (interpretation, review and editing). The final language check was provided by SK.

\section{REFERENCES}

Andersen, K. K., Azuma, N., Barnola, J. M., Bigler, M., Biscaye, P., Caillon, N., et al. (2004). High-resolution record of Northern Hemisphere climate extending into the last interglacial period. Nature 431 (7005), 147-151. doi: $10.1038 /$ nature 02805

Anechitei-Deacu, V., Timar-Gabor, A., Fitzsimmons, K., Veres, D., and Hambach, U. (2014). Multi-method luminescence investigations on quartz grains of different sizes extracted from a loess section in Southeast Romania interbedding the Campanian Ignimbrite ash layer. Geochronometria 41 (1), 1-14. doi:10.2478/s13386-013-0143-4

Antoine, P., Rousseau, D.-D., Degeai, J.-P., Moine, O., Lagroix, F., Fuchs, M., et al. (2013). High-resolution record of the environmental response to climatic variations during the Last Interglacial-Glacial cycle in Central Europe: the loess-palaeosol sequence of Dolní Věstonice (Czech Republic). Quat. Sci. Rev. 67, 17-38. doi:10.1016/j.quascirev.2013.01.014

Antoine, P., Lagroix, F., Jordanova, D., Jordanova, N., Lomax, J., Fuchs, M., et al. (2019). A remarkable late Saalian (MIS 6) loess (dust) accumulation in the lower Danube at Harletz (Bulgaria). Quat. Sci. Rev. 207, 80-100. doi:10.1016/j. quascirev.2019.01.005

Auclair, M., Lamothe, M., and Huot, S. (2003). Measurement of anomalous fading for feldspar IRSL using SAR. Radiat. Meas. 37 (4-5), 487-492. doi:10.1016/ s1350-4487(03)00018-0

Avram, A., Constantin, D., Veres, D., Kelemen, S., Obreht, I., Hambach, U., et al. (2020). Testing polymineral post-IR IRSL and quartz SAR-OSL protocols on middle to late Pleistocene loess at Batajnica, Serbia. Boreas 49 (3), 615-633. doi:10.1111/bor.12442

Basarin, B., Buggle, B., Hambach, U., Marković, S. B., Dhand, K. O. H., Kovačević, A., et al. (2014). Time-scale and astronomical forcing of Serbian loess-paleosol sequences. Global Planet. Change. 122, 89-106. doi:10.1016/j.gloplacha.2014.08.007

Berg, S. (2020). Radiocarbon data determined on sediments from loess paleosol sequence BAK. PANGAEA. doi:10.1594/PANGAEA.925059

\section{FUNDING}

The study was funded by the Deutsche Forschungsgemeinschaft (DFG, German Research Foundation) - Project number 57444011 - CRC 806 "Our Way to Europe." DV's work on tephrochronology of BAK was supported through a fellowship provided by the Alexander von Humboldt Foundation.

\section{ACKNOWLEDGMENTS}

The study is part of the CRC 806 which aims at understanding routes and timing of anatomically modern humans' migration from Africa to Europe. We thank all colleagues who make this CRC successful. We thank A. Zander of the Cologne Luminescence Laboratory for measuring the radionuclide concentrations of the dosimetry samples. We thank D. Haase for sharing the shapefiles of the loess distribution for Figure 1. This is IPGP contribution number 4178.

\section{SUPPLEMENTARY MATERIAL}

The Supplementary Material for this article can be found online at: https://www.frontiersin.org/articles/10.3389/feart.2020.598448/ full\#supplementary-material.

Biswas, R., Williams, M., Raj, R., Juyal, N., and Singhvi, A. (2013). Methodological studies on luminescence dating of volcanic ashes. Quat. Geochronol. 17, 14-25. doi:10.1016/j.quageo.2013.03.004

Bliedtner, M., von Suchodoletz, H., Schäfer, I. K., Welte, C., Salazar Quintero, G. A., Szidat, S., et al. (2020). Age and origin of leaf wax $n$-alkanes in fluvial sediment-paleosol sequences and implications for paleoenvironmental reconstructions. Hydrol. Earth Syst. Sci. 24 (4), 2105-2120. doi:10.5194/hess24-2105-2020

Bösken, J. J. and Schmidt, C. (2020). Direct and indirect luminescence dating of tephra: a review. J. Quat. Sci. 35 (1-2), 39-53. doi:10.1002/jqs.3160

Bösken, J., Klasen, N., Zeeden, C., Obreht, I., Marković, S. B., Hambach, U., et al. (2017). New luminescence-based geochronology framing the last two glacial cycles at the southern limit of European Pleistocene loess in Stalać (Serbia). Geochronometria 44 (1), 150-161. doi:10.1515/geochr-2015-0062

Bösken, J., Obreht, I., Zeeden, C., Klasen, N., Hambach, U., Sümegi, P., et al. (2019). High-resolution paleoclimatic proxy data from the MIS3/2 transition recorded in northeastern Hungarian loess. Quat. Int. 502, 95-107. doi:10.1016/j.quaint.2017.12.008

Bronk Ramsey, C. (2009). Bayesian analysis of radiocarbon dates. Radiocarbon 51 (1), 337-360. doi:10.1017/S0033822200033865

Buck, C. E., Cavanagh, W. G., and Litton, C. D. (1996). Bayesian approach to interpreting archaeological data. Chichester.

Buggle, B., Glaser, B., Zöller, L., Hambach, U., Marković, S., Glaser, I., et al. (2008) Geochemical characterization and origin of southeastern and eastern European loesses (Serbia, Romania, Ukraine). Quat. Sci. Rev. 27 (9-10), 1058-1075. doi:10.1016/j.quascirev.2008.01.018

Buggle, B., Hambach, U., Glaser, B., Gerasimenko, N., Marković, S., Glaser, I., et al. (2009). Stratigraphy and spatial and temporal paleoclimatic trends in Southeastern/Eastern European loess-paleosol sequences. Quat. Int. 196 (12), 86-106. doi:10.1016/j.quaint.2008.07.013

Buggle, B., Hambach, U., Kehl, M., Marković, S. B., Zöller, L., and Glaser, B. (2013). The progressive evolution of a continental climate in southeast-central European lowlands during the Middle Pleistocene recorded in loess paleosol sequences. Geology 41 (7), 771-774. doi:10.1130/g34198.1 
Buylaert, J. P., Jain, M., Murray, A. S., Thomsen, K. J., Thiel, C., and Sohbati, R. (2012). A robust feldspar luminescence dating method for Middle and Late Pleistocene sediments. Boreas 41 (3), 435-451. doi:10.1111/j.1502-3885.2012.00248.x

Chadima, M. and Hrouda, F. (2006). Remasoft 3.0 - a user-friendly paleomagnetic data browser and analyzer. Travaux Géophysiques 27, 20-21.

Channell, J. E., Singer, B. S., and Jicha, B. R. (2020). Timing of Quaternary geomagnetic reversals and excursions in volcanic and sedimentary archives. Quat. Sci. Rev. 228, 106114. doi:10.1016/j.quascirev.2019.106114

Constantin, D., Timar-Gabor, A., Veres, D., Begy, R., and Cosma, C. (2012). SAROSL dating of different grain-sized quartz from a sedimentary section in southern Romania interbedding the Campanian Ignimbrite/Y5 ash layer. Quat. Geochronol. 10, 81-86. doi:10.1016/j.quageo.2012.01.012

Constantin, D., Begy, R., Vasiliniuc, S., Panaiotu, C., Necula, C., Codrea, V., et al. (2014). High-resolution OSL dating of the Costineşti section (Dobrogea, SE Romania) using fine and coarse quartz. Quat. Int. 334, 20-29. doi:10.1016/j.quaint.2013.06.016

Constantin, D., Veres, D., Panaiotu, C., Anechitei-Deacu, V., Groza, S. M., Begy, R., et al. (2019). Luminescence age constraints on the Pleistocene-Holocene transition recorded in loess sequences across SE Europe. Quat. Geochronol. 49, 71-77. doi:10.1016/j.quageo.2018.07.011

Durcan, J. A., King, G. E., and Duller, G. A. (2015). DRAC: dose rate and age calculator for trapped charge dating. Quat. Geochronol. 28, 54-61. doi:10.1016/ j.quageo.2015.03.012

Emiliani, C. (1955). Pleistocene temperatures. J. Geol. 63 (6), 538-578. doi:10.1086/ 626295

Evans, M. E. and Heller, F. (2001). Magnetism of loess/palaeosol sequences: recent developments. Earth Sci. Rev. 54 (1), 129-144. doi:10.1016/s0012-8252(01)00044-7

Fenn, K., Durcan, J. A., Thomas, D. S., and Banak, A. (2020a). A 180 ka record of environmental change at Erdut (Croatia): a new chronology for the loess-palaeosol sequence and its implications for environmental interpretation. J. Quat. Sci. 35 (4), 582-593. doi:10.1002/jqs.3201

Fenn, K., Durcan, J. A., Thomas, D. S., Millar, I. L., and Marković, S. B. (2020b). Reanalysis of late Quaternary dust mass accumulation rates in Serbia using new luminescence chronology for loess-palaeosol sequence at Surduk. Boreas 49 (3), 634-652. doi:10.1111/bor.12445

Fitzsimmons, K. E. and Hambach, U. (2014). Loess accumulation during the last glacial maximum: evidence from Urluia, southeastern Romania. Quat. Int. 334, 74-85. doi:10.1016/j.quaint.2013.08.005

Fitzsimmons, K. E., Hambach, U., Veres, D., and Iovita, R. (2013). The Campanian Ignimbrite eruption: new data on volcanic ash dispersal and its potential impact on human evolution. PLoS One 8 (6), e65839. doi:10.1371/journal.pone.0065839

Frechen, M., Schweitzer, U., and Zander, A. (1996). Improvements in sample preparation for the fine grain technique. Ancient TL 14 (2), 15-17

Frînculeasa, A., Preda, B., and Heyd, V. (2015). Pit-graves, yamnaya and kurgans along the lower Danube: disentangling IVth and IIIrd millennium BC burial customs, equipment and chronology. Praehistorische Zeitschrift 90 (1-2), 45-113. doi:10.1515/pz-2015-0002

Gallet, S., Jahn, B.-m., and Torii, M. (1996). Geochemical characterization of the Luochuan loess-paleosol sequence, China, and paleoclimatic implications. Chem. Geol. 133 (1-4), 67-88. doi:10.1016/s0009-2541(96)00070-8

Giaccio, B., Hajdas, I., Isaia, R., Deino, A., and Nomade, S. (2017). High-precision ${ }^{14} \mathrm{C}$ and ${ }^{40} \mathrm{Ar} /{ }^{39} \mathrm{Ar}$ dating of the Campanian Ignimbrite (Y-5) reconciles the time-scales of climatic-cultural processes at 40 ka. Sci. Rep. 7 (1), 1-10. doi:10. 1038/srep45940

Govin, A., Capron, E., Tzedakis, P. C., Verheyden, S., Ghaleb, B., Hillaire-Marcel, C., et al. (2015). Sequence of events from the onset to the demise of the last interglacial: evaluating strengths and limitations of chronologies used in climatic archives. Quat. Sci. Rev., 129, 1-36. doi:10.1016/j.quascirev.2015. 09.018

Guérin, G., Frouin, M., Talamo, S., Aldeias, V., Bruxelles, L., Chiotti, L., et al. (2015). A multi-method luminescence dating of the palaeolithic sequence of $\mathrm{La}$ Ferrassie based on new excavations adjacent to the La Ferrassie 1 and 2 skeletons. J. Archaeol. Sci. 58, 147-166. doi:10.1016/j.jas.2015.01.019

Guérin, G., Mercier, N., and Adamiec, G. (2011). Dose-rate conversion factors: update. Ancient TL 29 (1), 5-8.

Haas, M., Bliedtner, M., Borodynkin, I., Salazar, G., Szidat, S., Eglinton, T. I., et al. (2017). Radiocarbon dating of leaf waxes in the loess-paleosol sequence Kurtak, central Siberia. Radiocarbon 59 (1), 165-176. doi:10.1017/rdc.2017.1
Haase, D., Fink, J., Haase, G., Ruske, R., Pécsi, M., Richter, H., et al. (2007). Loess in Europe-its spatial distribution based on a European loess map, scale 1: 2,500,000. Quat. Sci. Rev. 26 (9-10), 1301-1312. doi:10.1016/j.quascirev.2007.02.003

Haesaerts, P., Borziac, I., Chekha, V. P., Chirica, V., Drozdov, N. I., Koulakovska, L., et al. (2010). Charcoal and wood remains for radiocarbon dating upper pleistocene loess sequences in eastern Europe and central Siberia. Palaeogeogr. Palaeoclimatol. Palaeoecol. 291 (1), 106-127. doi:10.1016/j.palaeo.2010.03.034

Häggi, C., Zech, R., McIntyre, C. P., Zech, M., and Eglinton, T. I. (2014). On the stratigraphic integrity of leaf-wax biomarkers in loess paleosols. Biogeosciences 11 (9), 2455-2463. doi:10.5194/bg-11-2455-2014

Hambach, U., Rolf, C., and Schnepp, E. (2008). Magnetic dating of Quaternary sediments, volcanites and archaeological materials: an overview. Eiszeitalt. Ggw. Quat. Sci. J. 57 (2), 25-51. doi:10.3285/eg.57.1-2.2

Hanke, U. M., Wacker, L., Haghipour, N., Schmidt, M. W. I., Eglinton, T. I., and McIntyre, C. P. (2017). Comprehensive radiocarbon analysis of benzene polycarboxylic acids (BPCAs) derived from pyrogenic carbon in environmental samples. Radiocarbon 59 (4), 1103-1116. doi:10.1017/RDC.2017.44

Hatté, C., Pessenda, L. C., Lang, A., and Paterne, M. (2001). Development of accurate and reliable ${ }^{14} \mathrm{C}$ chronologies for loess deposits: application to the loess sequence of Nussloch (Rhine valley, Germany). Radiocarbon 43 (2B), 611-618. doi:10.1017/s0033822200041266

Heil, C. W., Jr, King, J. W., Zárate, M. A., and Schultz, P. H. (2010). Climatic interpretation of a 1.9 Ma environmental magnetic record of loess deposition and soil formation in the central eastern Pampas of Buenos Aires, Argentina. Quat. Sci. Rev. 29 (19-20), 2705-2718. doi:10.1016/j.quascirev.2010.06.024

Heller, F. and Liu, T.-S. (1986). Palaeoclimatic and sedimentary history from magnetic susceptibility of loess in China. Geophys. Res. Lett. 13, 1169-1172. doi:10.1029/gl013i011p01169

Heslop, D. and Roberts, A. P. (2020). Uncertainty propagation in hierarchical paleomagnetic reconstructions. J. Geophys. Res. 125 (6). doi:10.1029/2020JB019488

Huntley, D. (2006). An explanation of the power-law decay of luminescence. J. Phys. Condens. Matter. 18 (4), 1359. doi:10.1088/0953-8984/18/4/020

Huntley, D. J. and Baril, M. (1997). The K content of the K-feldspars being measured in optical dating or in thermoluminescence dating. Ancient TL 15 (1), 11-13.

ILEC (2019). Lake Balta Alba. Available at: https://wldb.ilec.or.jp/Lake/EUR-41. Date of access: 2020/07/20.

JAXA (2016). ALOS global digital surface model "ALOS world 3D - 30m (AW3D30)".

Jin, C. and Liu, Q. (2010). Reliability of the natural remanent magnetization recorded in Chinese loess. J. Geophys. Res. Solid Earth 115 (B4), B04103. doi:10. 1029/2009jb006703

Jipa, D. C. (2014). The conceptual sedimentary model of the Lower Danube loess basin: sedimentogenetic implications. Quat. Int. 351, 14-24. doi:10.1016/j. quaint.2013.06.008

King, G. E., Burow, C., Roberts, H. M., and Pearce, N. J. (2018). Age determination using feldspar: evaluating fading-correction model performance. Radiat. Meas. 119, 58-73. doi:10.1016/j.radmeas.2018.07.013

Kirschvink, J. (1980). The least-squares line and plane and the analysis of palaeomagnetic data. Geophys. J. Int. 62 (3), 699-718. doi:10.1111/j.1365246x.1980.tb02601.x

Klasen, N., Kehl, M., Mikdad, A., Brückner, H., and Weniger, G.-C. (2018). Chronology and formation processes of the middle to upper palaeolithic deposits of Ifri n'Ammar using multi-method luminescence dating and micromorphology. Quat. Int. 485, 89-102. doi:10.1016/j.quaint.2017.10.043

Kohfeld, K. and Harrison, S. (2003). Glacial-interglacial changes in dust deposition on the Chinese loess plateau. Quat. Sci. Rev. 22 (18-19), 1859-1878. doi:10. 1016/s0277-3791(03)00166-5

Korte, M., Brown, M. C., Panovska, S., and Wardinski, I. (2019). Robust characteristics of the Laschamp and Mono Lake geomagnetic excursions: results from global field models. Front. Earth Sci. 7 (86), 1-21. doi:10.3389/feart.2019.00086

Krbetschek, M., Rieser, U., Zöller, L., and Heinicke, J. (1994). Radioactive disequilibria in palaeodosimetric dating of sediments. Radiat. Meas. 23 (23), 485-489. doi:10.1016/1350-4487(94)90083-3

Kusch, S., Rethemeyer, J., Schefuß, E., and Mollenhauer, G. (2010). Controls on the age of vascular plant biomarkers in Black Sea sediments. Geochim. Cosmochim. Acta 74, 7031-7047. doi:10.1016/j.gca.2010.09.005

Laj, C. and Kissel, C. (2015). An impending geomagnetic transition? Hints from the past. Front. Earth Sci. 3 (61), 1-10. doi:10.3389/feart.2015.00061 
Laj, C., Kissel, C., and Beer, J. (2004). High resolution global paleointensity stack since $75 \mathrm{kyr}$ (GLOPIS-75) calibrated to absolute values. Geophys. Monogr. 145, 255-265. doi:10.1029/145gm19

Lauer, T., Frechen, M., Vlaminck, S., Kehl, M., Sharifi, J., Rolf, C., et al. (2016). The Agh Band loess-palaeosol sequence in Northern Iran - a detailed archive for climate and environmental change during the last and penultimate glacialinterglacial cycles. Vienna Austria: 2016EGUGA..18.2488L.

Levi, S. and Banerjee, S. K. (1976). On the possibility of obtaining relative paleointensities from lake sediments. Earth Planet Sci. Lett. 29 (1), 219-226. doi:10.1016/0012-821x(76)90042-x

Li, G., Xia, D., Appel, E., Lu, H., Wang, Y., Jia, J., et al. (2020). Characteristics of a relative paleointensity record from loess deposits in arid central Asia and chronological implications. Quat. Geochronol. 55, 101034. doi:10. 1016/j.quageo.2019.101034

Liu, Q., Banerjee, S. K., Jackson, M. J., Deng, C., Pan, Y., and Zhu, R. (2005). Interprofile correlation of the Chinese loess/paleosol sequences during Marine Oxygen Isotope Stage 5 and indications of pedogenesis. Quat. Sci. Rev. 24, 195-210. doi:10.1016/j.quascirev.2004.07.021

Liu, Q., Jin, C., Hu, P., Jiang, Z., Ge, K., and Roberts, A. P. (2015). Magnetostratigraphy of Chinese loess-paleosol sequences. Earth Sci. Rev. 150, 139-167. doi:10.1016/j.earscirev.2015.07.009

Lomax, J., Fuchs, M., Antoine, P., Rousseau, D. D., Lagroix, F., Hatté, C., et al. (2019). A luminescence-based chronology for the Harletz loess sequence, Bulgaria. Boreas 48 (1), 179-194. doi:10.1111/bor.12348

Lowe, J. J. and Walker, M. J. (2014). Reconstructing quaternary environments: London and New York: Routledge.

Maher, B. A. (1999). "Palaeomonsoons I: the magnetic record of palaeoclimate in the terrestrial loess and palaeosol sequences," in Quaternary climates, environments and magnetism. Editors B.-A. Maher and R. Thompson (Cambridge University Press), 81-125.

Marković, S. B., Hambach, U., Catto, N., Jovanović, M., Buggle, B., Machalett, B., et al. (2009). Middle and late Pleistocene loess sequences at Batajnica, Vojvodina, Serbia. Quat. Int. 198 (1-2), 255-266. doi:10.1016/j.quaint.2008.12.004

Marković, S. B., Fitzsimmons, K. E., Sprafke, T., Gavrilović, D., Smalley, I. J., Jović, V., et al. (2016). The history of Danube loess research. Quat. Int. 399, 86-99. doi:10.1016/j.quaint.2015.09.071

Marković, S. B., Stevens, T., Kukla, G. J., Hambach, U., Fitzsimmons, K. E., Gibbard, P., et al. (2015). Danube loess stratigraphy - towards a pan-European loess stratigraphic model. Earth Sci. Rev. 148, 228-258. doi:10.1016/j.earscirev.2015.06.005

Matsumoto, K., Kawamura, K., Uchida, M., and Shibata, Y. (2007). Radiocarbon content and stable carbon isotopic ratios of individual fatty acids in subsurface soil: implication for selective microbial degradation and modification of soil organic matter. Geochem. J. 41 (6), 483-492. doi:10.2343/geochemj.41.483

Moine, O., Antoine, P., Hatté, C., Landais, A., Mathieu, J., Prud'homme, C., et al. (2017). The impact of last glacial climate variability in West-European loess revealed by radiocarbon dating of fossil earthworm granules. Proc. Natl. Acad. Sci. U.S.A. 114 (24), 6209-6214. doi:10.1073/pnas.1614751114

Murray, A. S., Thomsen, K. J., Masuda, N., Buylaert, J. P., and Jain, M. (2012). Identifying well-bleached quartz using the different bleaching rates of quartz and feldspar luminescence signals. Radiat. Meas. 47 (9), 688-695. doi:10.1016/j. radmeas.2012.05.006

Murray, A. S. and Wintle, A. G. (2000). Luminescence dating of quartz using an improved single-aliquot regenerative-dose protocol. Radiat. Meas. 32 (1), 57-73. doi:10.1016/s1350-4487(99)00253-x

Murray, A. S. and Wintle, A. G. (2003). The single aliquot regenerative dose protocol: potential for improvements in reliability. Radiat. Meas. 37 (4), 377-381. doi:10.1016/s1350-4487(03)00053-2

Necula, C., Dimofte, D., and Panaiotu, C. (2015). Rock magnetism of a loesspalaeosol sequence from the western Black Sea shore (Romania). Geophys. J. Int. 202 (3), 1733-1748. doi:10.1093/gji/ggv250

Nett, J., Oppermann, L., and Klasen, N. (2020). OSL data of the Balta Alba Kurgan loess-paleosol sequence, Romania. CRC806-Database. doi:10.5880/SFB806.54

Nițu, E.-C., Cârciumaru, M., Nicolae, A., Cîrstina, O., Lupu, F. I., and Leu, M. (2019). Mobility and social identity in the Mid Upper Paleolithic: new personal ornaments from Poiana Cireșului (Piatra Neamț, Romania). PLoS One. 14 (4), e0214932. doi:10.1371/journal.pone.0214932

Novothny, Á., Frechen, M., Horváth, E., Wacha, L., and Rolf, C. (2011). Investigating the penultimate and last glacial cycles of the Süttő loess section (Hungary) using luminescence dating, high-resolution grain size and magnetic susceptibility data. Quat. Int. 234 (1-2), 75-85. doi:10.1016/j.quaint.2010.08.002

Obreht, I., Hambach, U., Veres, D., Zeeden, C., Bösken, J., Stevens, T., et al. (2017). Shift of large-scale atmospheric systems over Europe during late MIS 3 and implications for Modern Human dispersal. Sci. Rep. 7 (1), 5848. doi:10.1038/s41598-017-06285-x

Parnell, A. (2018). Bchron: radiocarbon dating, age-depth modelling, relative sea level rate estimation and non-parametric phase modelling.

Parnell, A. C., Haslett, J., Allen, J. R., Buck, C. E., and Huntley, B. (2008). A flexible approach to assessing synchroneity of past events using Bayesian reconstructions of sedimentation history. Quat. Sci. Rev. 27 (19-20), 1872-1885. doi:10.1016/j. quascirev.2008.07.009

Pfeifer, L. S., Hinnov, L., Zeeden, C., Rolf, C., Laag,, C., and Soreghan, G. S. (2020). Rock magnetic cyclostratigraphy of permian loess in eastern equatorial pangea (Salagou formation, South-Central France). Front. Earth Sci. 8 (241). doi:10. 3389/feart.2020.00241

Pigati, J. S., McGeehin, J. P., Muhs, D. R., and Bettis, E. A., III (2013). Radiocarbon dating late Quaternary loess deposits using small terrestrial gastropod shells. Quat. Sci. Rev. 76, 114-128. doi:10.1016/j.quascirev.2013.05.013

Prescott, J. R. and Hutton, J. T. (1994). Cosmic ray contributions to dose rates for luminescence and ESR dating: large depths and long-term time variations. Radiat. Meas. 23 (2-3), 497-500. doi:10.1016/1350-4487(94)90086-8

$\mathrm{R}$ Core Team (2020). R: a language and environment for statistical computing: $\mathrm{R}$ Core Team.

Reimer, P. J., Brown, T. A., and Reimer, R. W. (2004). Discussion: reporting and calibration of post-bomb ${ }^{14} \mathrm{C}$ data. Radiocarbon 46 (3), 1299-1304. doi:10.1017/ s0033822200033154

Reimer, P. J., Austin, W. E. N., Bard, E., Bayliss, A., Blackwell, P. G., Bronk Ramsey, C., et al. (2020). The INTCAL20 northern hemisphere radiocarbon age calibration curve (0-55 cal kBP). Radiocarbon 62 (4), 725-757. doi:10.1017/rdc.2020.41

Rethemeyer, J., Gierga, M., Heinze, S., Stolz, A., Wotte, A., Wischhöfer, P., et al. (2019). Current sample preparation and analytical capabilities of the radiocarbon laboratory at CologneAMS. Radiocarbon 61 (5), 1449-1460. doi:10.1017/RDC.2019.16

Roberts, A. P. and Winklhofer, M. (2004). Why are geomagnetic excursions not always recorded in sediments? Constraints from post-depositional remanent magnetization lock-in modelling. Earth Planet Sci. Lett. 227 (3-4), 345-359. doi:10.1016/j.epsl.2004.07.040

Roberts, H. M. (2008). The development and application of luminescence dating to loess deposits: a perspective on the past, present and future. Boreas 37 (4), 483-507. doi:10.1111/j.1502-3885.2008.00057.x

Rolf, C., Hambach, U., Novothny, Á., Horváth, E., and Schnepp, E. (2014). Dating of a last glacial loess sequence by relative geomagnetic palaeointensity: a case study from the middle Danube basin (Süttő, Hungary). Quat. Int. 319, 99-108. doi:10.1016/j.quaint.2013.08.050

Rousseau, D.-D., Antoine, P., Boers, N., Lagroix, F., Ghil, M., Lomax, J., et al. (2020). Dansgaard-Oeschger-like events of the penultimate climate cycle: the loess point of view. Clim. Past. 16 (2), 713-727. doi:10.5194/cp-16-713-2020

Scheidt, S., Hambach, U., Laag, C., and Monnens, F. (2020). [Dataset]: Paleomagnetic and mineral magnetic data of the loess paleosol record Balta Alba Kurgan. PANGAEA. https://doi.org/10.1594/PANGAEA.922831

Schmidt, C., Bösken, J., and Kolb, T. (2018). Is there a common alpha-efficiency in polymineral samples measured by various infrared stimulated luminescence protocols? Geochronometria 45 (1), 160-172. doi:10.1515/geochr-2015-0095

Smalley, I. J. and Leach, J. A. (1978). The origin and distribution of the loess in the Danube basin and associated regions of East-Central Europe - a review. Sediment. Geol. 21 (1), 1-26. doi:10.1016/0037-0738(78)90031-3

Smalley, I., O'Hara-Dhand, K., Wint, J., Machalett, B., Jary, Z., and Jefferson, I. (2009). Rivers and loess: the significance of long river transportation in the complex event-sequence approach to loess deposit formation. Quat. Int. 198 (1), 7-18. doi:10.1016/j.quaint.2008.06.009

Song, Y., Li, C., Zhao, J., Cheng, P., and Zeng, M. (2012). A combined luminescence and radiocarbon dating study of the Ili loess, central Asia. Quat. Geochronol. 10, 2-7. doi:10.1016/j.quageo.2012.04.005

Song, Y., Lai, Z., Li, Y., Chen, T., and Wang, Y. (2015). Comparison between luminescence and radiocarbon dating of late Quaternary loess from the Ili basin in central Asia. Quat. Geochronol. 30, 405-410. doi:10.1016/j.quageo.2015.01.012

Song, Y., Guo, Z., Marković, S., Hambach, U., Deng, C., Chang, L., et al. (2018a). Magnetic stratigraphy of the Danube loess: a composite Titel-Stari Slankamen 
loess section over the last one million years in Vojvodina, Serbia. J. Asian Earth Sci. 155, 68-80. doi:10.1016/j.jseaes.2017.11.012

Song, Y., Luo, D., Du, J., Kang, S., Cheng, P., Fu, C., et al. (2018b). Radiometric dating of late Quaternary loess in the northern piedmont of South Tianshan Mountains: implications for reliable dating. Geol. J. 53 (S2), 417-426. doi:10. $1002 / g j .3129$

Staubwasser, M., Drăgușin, V., Onac, B. P., Assonov, S., Ersek, V., Hoffmann, D. L., et al. (2018). Impact of climate change on the transition of Neanderthals to modern humans in Europe. Proc. Natl. Acad. Sci. U.S.A. 115 (37), 9116-9121. doi:10.1073/pnas.1808647115

Stolz, A., Dewald, A., Heinze, S., Altenkirch, R., Hackenberg, G., Herb, S., et al. (2019). Improvements in the measurement of small ${ }^{14} \mathrm{CO}_{2}$ samples at CologneAMS. Nucl. Instrum. Methods Phys. Res. Sect. B Beam Interact. Mater. Atoms. 439, 70-75. doi:10.1016/j.nimb.2018.12.008

Sümegi, P., Gulyás, S., Molnár, D., Szilágyi, G., Sümegi, B. P., Töröcsik, T., et al. (2020). ${ }^{14} \mathrm{C}$ dated chronology of the thickest and best resolved loess/paleosol record of the LGM from SE Hungary based on comparing precision and accuracy of agedepth models. Radiocarbon 62 (2), 403-417. doi:10.1017/RDC.2019.154

Svensson, A., Andersen, K. K., Bigler, M., Clausen, H. B., Dahl-Jensen, D., Davies, S. M., et al. (2008). A 60000 year Greenland stratigraphic ice core chronology. Clim. Past. 4 (1), 47-57. doi:10.5194/cp-4-47-2008

Tauxe, L. (2010). Essentials of paleomagnetism. University of California Press, Berkeley.

Tecsa, V., Gerasimenko, N., Veres, D., Hambach, U., Lehmkuhl, F., Schulte, P., et al. (2020). Revisiting the chronostratigraphy of late Pleistocene loess-paleosol sequences in southwestern Ukraine: OSL dating of Kurortne section. Quat. Int. 542, 65-79. doi:10.1016/j.quaint.2020.03.001

Telford, R. J., Heegaard, E., and Birks, H. J. B. (2004). All age-depth models are wrong: but how badly? Quat. Sci. Rev. 23 (1), 1-5. doi:10.1016/j.quascirev. 2003.11.003

Thiel, C., Buylaert, J.-P., Murray, A., Terhorst, B., Hofer, I., Tsukamoto, S., et al. (2011). Luminescence dating of the Stratzing loess profile (Austria) - Testing the potential of an elevated temperature post-IR IRSL protocol. Quat. Int. 234 (1-2), 23-31. doi:10.1016/j.quaint.2010.05.018

Thomsen, K. J., Murray, A. S., Jain, M., and Bøtter-Jensen, L. (2008). Laboratory fading rates of various luminescence signals from feldspar-rich sediment extracts. Radiat. Meas. 43 (9), 1474-1486. doi:10.1016/j.radmeas.2008.06.002

Timar-Gabor, A., Vandenberghe, D. A. G., Vasiliniuc, S., Panaoitu, C. E., Panaiotu, C. G., Dimofte, D., et al. (2011). Optical dating of Romanian loess: a comparison between silt-sized and sand-sized quartz. Quat. Int. 240 (1), 62-70. doi:10.1016/ j.quaint.2010.10.007

Timar-Gabor, A., Panaiotu, C., Vereș, D., Necula, C., and Constantin, D. (2017). "The lower Danube loess, new age constraints from luminescence dating, magnetic proxies and isochronous tephra markers," in Landform dynamics and evolution in Romania. Editors M. Radoane and A. Vespremeanu-Stroe (Cham: Springer International Publishing), 679-697.

Trachsel, M. and Telford, R. J. (2017). All age-depth models are wrong, but are getting better. Holocene 27 (6), 860-869. doi:10.1177/0959683616675939

Trumbore, S. (2009). Radiocarbon and soil carbon dynamics. Annu. Rev. Earth Planet Sci. 37, 47-66. doi:10.1146/annurev.earth.36.031207.124300

Újvári, G., Kovács, J., Varga, G., Raucsik, B., and Marković, S. B. (2010). Dust flux estimates for the Last Glacial Period in East Central Europe based on terrestrial records of loess deposits: a review. Quat. Sci. Rev. 29 (23), 3157-3166. doi:10. 1016/j.quascirev.2010.07.005

Újvári, G., Kovács, J., Varga, G., Molnár, M., and Novothny, Á. (2014a). Late Pleistocene millennial scale cycles of aeolian sedimentation in the Dunaszekcső loess record, south Hungary: preliminary data and interpretations. Sci. Annals Stefan cel Mare Univ. Suceava Geography Ser. 24 (2), 168-169. doi:10.4316/ GEOREVIEW.2014.0.0.244

Újvári, G., Molnár, M., Novothny, A., and Kovacs, J. (2014b). Lessons from the AMS ${ }^{14} \mathrm{C}$ and OSL/IRSL-dating of the Dunaszekcsö loess record. Hungary.

Újvári, G., Molnár, M., Novothny, Á., Páll-Gergely, B., Kovács, J., and Várhegyi, A. (2014c). AMS ${ }^{14} \mathrm{C}$ and OSL/IRSL dating of the Dunaszekcső loess sequence (Hungary): chronology for 20 to $150 \mathrm{ka}$ and implications for establishing reliable age-depth models for the last $40 \mathrm{ka}$. Quat. Sci. Rev. 106, 140-154. doi:10.1016/j.quascirev.2014.06.009

Újvári, G., Stevens, T., Molnár, M., Demény, A., Lambert, F., Varga, G., et al. (2017). Coupled European and Greenland last glacial dust activity driven by
North Atlantic climate. Proc. Natl. Acad. Sci. U.S.A. 114 (50), E10632-E10638. doi:10.1073/pnas.1712651114

van der Voort, T. S., Zell, C. I., Hagedorn, F., Feng, X., McIntyre, C. P., Haghipour, N., et al. (2017). Diverse soil carbon dynamics expressed at the molecular level. Geophys. Res. Lett. 44 (11840-11), 850. doi:10.1002/2017gl076188

Veres, D., Lane, C. S., Timar-Gabor, A., Hambach, U., Constantin, D., Szakács, A., et al. (2013). The Campanian Ignimbrite/Y5 tephra layer a regional stratigraphic marker for Isotope Stage 3 deposits in the Lower Danube region, Romania. Quat. Int. 293, 22-33. doi:10.1016/j.quaint.2012. 02.042

Veres, D., Tecsa, V., Gerasimenko, N., Zeeden, C., Hambach, U., and Timar-Gabor, A. (2018). Short-term soil formation events in last glacial east European loess, evidence from multi-method luminescence dating. Quat. Sci. Rev. 200, 34-51. doi:10.1016/j.quascirev.2018.09.037

Wallinga, J., Murray, A., and Duller, G. (2000). Underestimation of equivalent dose in single-aliquot optical dating of feldspars caused by preheating. Radiat. Meas. 32 (5-6), 691-695. doi:10.1016/s1350-4487(00)00127-x

Wiesenberg, G. L., Schmidt, M., and Schwark, L. (2008). Plant and soil lipid modifications under elevated atmospheric $\mathrm{CO}_{2}$ conditions: I. Lipid distribution patterns. Org. Geochem. 39 (1), 91-102. doi:10.1016/j. orggeochem.2007.09.005

Wiesenberg, G. L., Schneckenberger, K., Schwark, L., and Kuzyakov, Y. (2012). Use of molecular ratios to identify changes in fatty acid composition of Miscanthus $\times$ giganteus (Greef et Deu.) plant tissue, rhizosphere and root-free soil during a laboratory experiment. Org. Geochem. 46, 1-11. doi:10.1016/j. orggeochem.2012.01.010

Wintle, A. G. (1973). Anomalous fading of thermo-luminescence in mineral samples. Nature 245 (5421), 143-144. doi:10.1038/245143a0

Zech, M., Kreutzer, S., Zech, R., Goslar, T., Meszner, S., McIntyre, C., et al. (2017). Comparative ${ }^{14} \mathrm{C}$ and OSL dating of loess-paleosol sequences to evaluate postdepositional contamination of n-alkane biomarkers. Quat. Res. 87, 180-189. doi:10.1017/qua.2016.7

Zeeden, C., Dietze, M., and Kreutzer, S. (2018a). Discriminating luminescence age uncertainty composition for a robust Bayesian modelling. Quat. Geochronol. 43, 30-39. doi:10.1016/j.quageo.2017.10.001

Zeeden, C., Hambach, U., Obreht, I., Hao, Q., Abels, H. A., Veres, D., et al. (2018b). Patterns and timing of loess-paleosol transitions in Eurasia: constraints for paleoclimate studies. Global Planet. Change. 162, 1-7. doi:10.1016/j.gloplacha. 2017.12.021

Zeeden, C., Hambach, U., Veres, D., Fitzsimmons, K., Obreht, I., Bösken, J., et al. (2018c). Millennial scale climate oscillations recorded in the Lower Danube loess over the last glacial period. Palaeogeogr. Palaeoclimatol. Palaeoecol. 509, 164-181. doi:10.1016/j.palaeo.2016.12.029

Zeeden, C. and Hambach, U. (2020). [Dataset]: Paleomagnetic of Poiana Ciresului/Romania. PANGAEA. https://doi.org/10.1594/PANGAEA. 918106

Zeeden, C., Hambach, U., Steguweit, L., Fülling, A., Anghelinu, M., and Zöller, L. (2009). Using the relative intensity variation of the Earth's magnetic palaeofield as correlative dating technique: a case study from loess with Upper Palaeolithic cultural layers at Poiana Cireşului, Romania. Quartär 56, 175-185. doi:10.7485/QU56_10

Zeeden, C., Hambach, U., Steguweit, L., and Anghelinu, M. (2011). Loess stratigraphy using palaeomagnetism: application to the Poiana Cireșului archaeological site (Romania). Quat. Int. 240 (1-2), 100-107. doi:10.1016/j. quaint.2010.08.018

Zeeden, C., Hambach, U., Veres, D., Fitzsimmons, K., Obreht, I., Bösken, J., et al. (2019). Corrigendum to "Millennial scale climate oscillations recorded in the Lower Danube loess over the last glacial period". Palaeogeogr. Palaeoclimatol. Palaeoecol. 509, 15-117. doi:10.1016/j.palaeo.2019.01.026

Zeeden, C., Hambach, U., Veres, D., Fitzsimmons, K., Obreht, I., Bösken, J., et al. (2016). [Dataset]: Physical properties and fine fraction from Loess at Rasova/lower Danube. PANGAEA. https://doi.org/10.1594/PANGAEA. 870532

Zeeden, C., Obreht, I., Veres, D., Kaboth-Bahr, S., Hošek, J., Marković, S. B., et al. (2020). Smoothed millennial-scale palaeoclimatic reference data as unconventional comparison targets: application to European loess records. Sci. Rep. 10 (1), 5455. doi:10.1038/s41598-020-61528-8 
Zelles, L. (1999). Fatty acid patterns of phospholipids and lipopolysaccharides in the characterisation of microbial communities in soil: a review. Biol. Fertil. Soils 29 (2), 111-129. doi:10.1007/s003740050533

Zhang, H., Ait Brahim, Y., Li, H. Z., Jingyao, G., Tian, Y., Baker, J., et al. (2019). The Asian summer monsoon: teleconnections and forcing mechanisms $-\mathrm{A}$ review from Chinese speleothem $\delta^{18} \mathrm{O}$ records. Quaternary 2, 26. doi:10.3390/quat2030026

Zhang, J., Rolf, C., Wacha, L., Tsukamoto, S., Durn, G., and Frechen, M. (2018). Luminescence dating and palaeomagnetic age constraint of a last glacial loess-palaeosol sequence from Istria, Croatia. Quat. Int. 494, 19-33. doi:10.1016/j.quaint.2018.05.045

Zijderveld, J. (1967). "AC demagnetization of rocks: analysis of results," in Methods in paleomagnetism. Editors D. Collinson, K. Creer, and S. Runcorn (New York: Elsevier), $254-286$.
Conflict of Interest: The authors declare that the research was conducted in the absence of any commercial or financial relationships that could be construed as a potential conflict of interest.

Copyright $\odot 2021$ Scheidt, Berg, Hambach, Klasen, Pötter, Stolz, Veres, Zeeden, Brill, Brückner, Kusch, Laag, Lehmkuhl, Melles, Monnens, Oppermann, Rethemeyer and Nett. This is an open-access article distributed under the terms of the Creative Commons Attribution License (CC BY). The use, distribution or reproduction in other forums is permitted, provided the original author $(s)$ and the copyright owner $(s)$ are credited and that the original publication in this journal is cited, in accordance with accepted academic practice. No use, distribution or reproduction is permitted which does not comply with these terms. 